\title{
INVITED SURVEY PAPER Smart Power Supply Systems for Mission Critical Facilities
}

\section{Keiichi HIROSE $^{\dagger \text { a) }}$ and Tadatoshi BABASAKI ${ }^{\dagger \dagger b)}$, Members}

SUMMARY To develop the advanced and rich life, and the also economy and social activity continuously, various types of energy are necessary. At the same time, to protect the global environment and to prevent the depletion of natural resources, the effective and moreover efficient use of energy is becoming important. Electric power is one of the most important forms of energy for our life and society. This paper describes topics and survey results of technical trends regarding the electric power supply systems which are playing a core role as the important infrastructure to support the emergence of information-oriented society. Specifically, the power supply systems that enhance high power quality and reliability $(\mathrm{PQR})$ are important for the steady growth of information and communication services. The direct current (DC) power, which has been used for telecommunications power systems and information and communications technologies (ICT), enables existing utilities' grid and distributed energy resources to keep a balance between supply and demand of small-scaled power systems or microgirds. These techniques are expected to be part of smartgrid technologies and facilitate the installation of distributed generators in mission critical facilities.

key words: electirc power, power quality, reliability, micro grid, smart grid, DC power, mission critical facilities

\section{Changes in Power Use}

Electric power grids are an important part of the social infrastructure and have undergone remarkable development since their industrial introduction in the latter half of the 19th century [1]. Our consumption of energy has been increasing along with human and social development, and the increased demand for electric power has been particularly striking. For that reason, the electrification ratio, which is the proportion of primary power occupied by electricity, has been increasing continuously [2].

The trend in electric power demand in Japan (Fig. 1) shows that demand increased by a factor of about three in the 30 years from 1970 to 2000 , from 310 billion $\mathrm{kWh}$ to 940 billion $\mathrm{kWh}$. While the annual rate of increase in those 30 years was $3.8 \%$, that rate is expected to drop to $1.0 \%$ per year for the 30 years beginning in 2000 . Electricity is safe and clean and offers many advantages, such as ease of conversion and high efficiency, and the forms of use are expected to steadily expand from now into the future. The trend in electrification in Japan is shown in Fig. 2, where we

\footnotetext{
Manuscript received August 2, 2011.

Manuscript revised October 28, 2011.

${ }^{\dagger}$ The author is with the Research and Development Headquarters, NTT Facilities, Inc., Tokyo, 170-0004 Japan.

${ }^{\dagger \dagger}$ The author is with NTT Energy and Environment Systems Laboratories, NTT Corporation, Musashino-shi, 180-8585 Japan.

a) E-mail: hirose36@ntt-f.co.jp

b) E-mail: babasaki.tadatoshi@lab.ntt.co.jp

DOI: 10.1587/transcom.E95.B.755
}

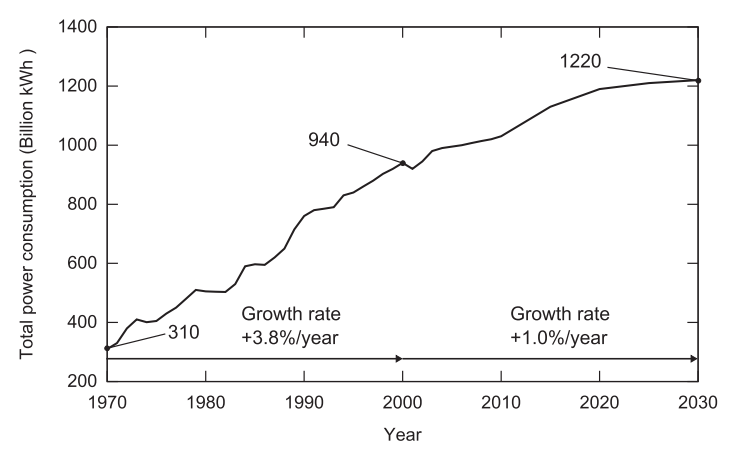

Fig. 1 Trend of total power consumption in Japan.

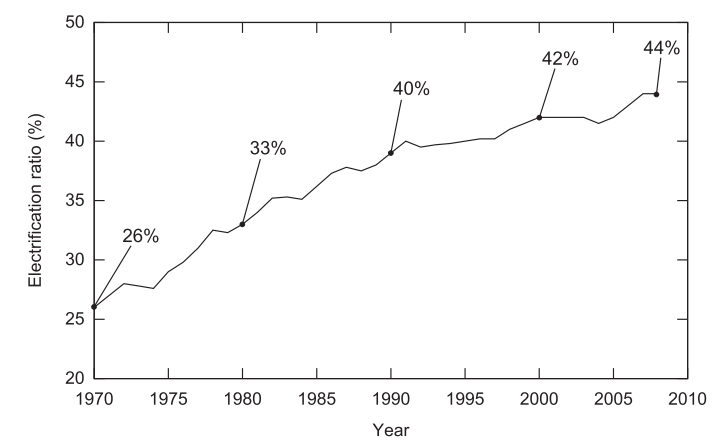

Fig. 2 Trend of electrification ratio in Japan.

see an increase from $26 \%$ for 1970 to $44 \%$ for 2008 , and that increasing trend is expected to continue up to 2030.

Accordingly, although the rate of increase in demand for electrical power in Japan has been decreasing in recent years, the electrification ratio continues to increase and the social role and importance of electricity are likely to be even greater in the future. If we focus on the form of using electrical power from the perspective of the use and consumption of power, which is to say from the demand side rather than from the standpoint of power generation and distribution as seen by the power industry, then a great change in recent years can be seen. Up to roughly the 1970s, electric power was used mainly for lighting, heating, and motors.

The trend changed after the 1980s, and currently air conditioning, refrigeration, cooking appliances and other electromechanical devices that have incorporated semiconductors, power electronics technology, and digital electronics such as TV sets, audio-visual systems and personal computers have come into widespread use. (We refer to such equipment generically as 'digital load devices' in this pa- 
per). With advances in information and communications technologies (ICT), the trend in overall power consumption in recent years has been a continuing steep increase in the use of digital load devices in a wider range of fields, including, industry, public corporations, economics, and medicine.

For example, microcomputers sold at 1.2 million units per three months in 1993, but only five years later that rate had tripled, and digital load devices had permeated daily life and industry [3]. In the United States for example, digital load devices accounted for $10 \%$ of all load devices in 2000 , but that proportion is expected to by $70 \%$ by 2020 [4]. These digital load devices are extremely sensitive to power quality factors such as voltage fluctuation and momentary power interruptions, and dealing with those vulnerabilities has become problematic.

Thus, the ways in which electrical power is used are changing such that most load devices are vulnerable to voltage fluctuation and other such factors of power quality. A power system that provides highly-reliable, high-quality power is required so that the mass-marketed digital load devices that are in use can continue stable operation without stopping unexpectedly, malfunctioning or incurring other problems. What measures can be taken to provide a stable power system is an issue in the field of electrical power grids.

\section{Improving the Power Quality and Reliability (PQR)}

Electrical power is generally supplied to a particular region by an electric power company, and that company is responsible for maintaining a reliable supply of power. In Japan, too, the efforts of electric companies and the manufacturers of plant and facilities to improve the power quality and reliability (PQR) have spanned many years. Data showing the trend for the frequency of occurrence and duration of power interruptions per consumer per year in Japan are presented in Fig. 3; power interruption duration data for various countries are compared in Fig. 4. Japan has achieved a level of power system reliability that is very high relative to other countries by reducing the number and duration of power interruptions [5], [6].

Previously, the most important issue was stability of power supply for both the supply side and the demand side, and reliability was generally measured in terms of frequency and duration of power interruption [7]. Nevertheless, the use of digital load devices that are vulnerable to voltage fluctuation has increased year by year, and the demand is for power quality that involves normal voltage at the waveform level as well as reliability that involves simply whether or not voltage is present [8].

Figure 5 shows relation between power qulaity and reliability. Reliability can be recognized as one part of the power quality. Reliability of the power supply can be expressed both interruption frequencies and availabiliy for the relation between up-time and down-time.

Various events that occur in the power grid or in the load equipment itself can disrupt the voltage magnitude

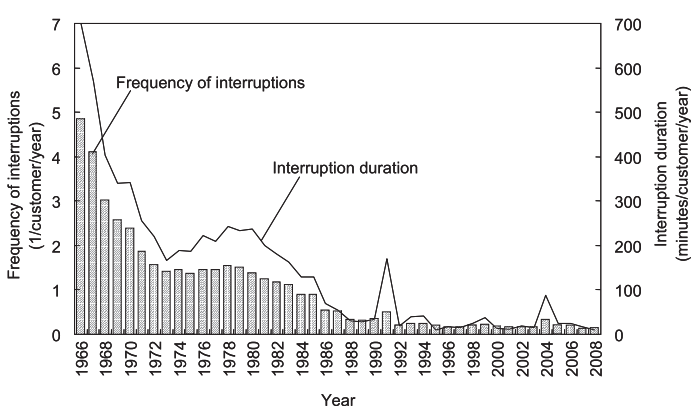

Fig. 3 Trend of power supply reliability in Japan.

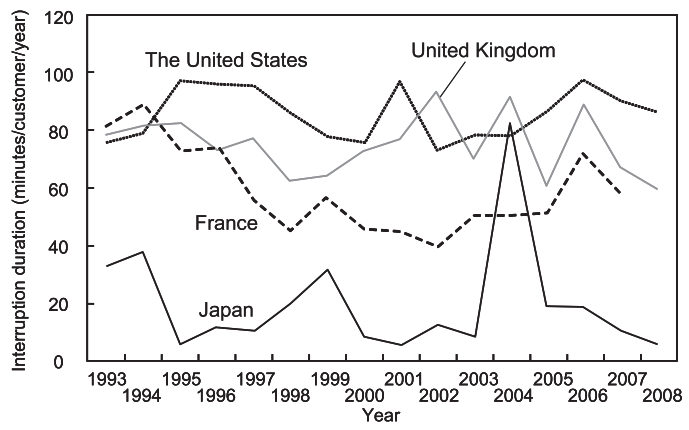

Fig. 4 Comparison of average interruption duration.

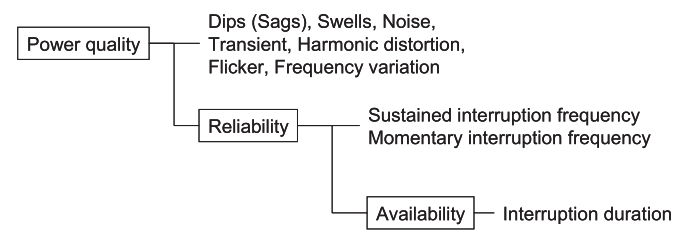

Fig. 5 Concept of power quality and reliability.

or waveform, and sometimes the frequency as well. The generic name for these factors is 'power quality' [9]. A decrease in power quality can harm industrial facilities and equipment or facilities in consumer homes, or otherwise create unintentional inconvenience. Power quality itself is a very broad concept. Although it has been defined in many ways in different countries, areas, applied specifications and standards and for various kinds of facilities and equipment, a generally-accepted definition is the one from reference [10], "any power problem manifested in voltage, current, or frequency deviations that results in failure or malfunction of customer equipment". The main phenomena that affect power quality are listed in Table 1 [10], where they are classified temporally as transient events that last less than a few seconds, short-duration events that last from a few cycles to one minute or less, and long-duration events that last for a longer time. The table also classifies steady-state voltage imbalances, waveform distortions, voltage fluctuations, and frequency variations. The economic loss for both suppliers and consumers of power from damage to facilities or the stopping or malfunctioning of load devices or systems due to decreases in power quality and the costs of measures for 
Table 1 Categories and characteristics of power system electromagnetic phenomena [10].

\begin{tabular}{|c|c|}
\hline Categories & Typical duration, voltage magunitude \\
\hline \multicolumn{2}{|l|}{ 1.0 Transients } \\
\hline \multicolumn{2}{|l|}{ 1.1 Impulsive } \\
\hline 1.1.1 Nanosecond & $<50 \mathrm{~ns}$ \\
\hline 1.1.2 Microsecond & $50 \mathrm{~ns}-1 \mathrm{~ms}$ \\
\hline 1.1.3 Millisecond & $>1 \mathrm{~ms}$ \\
\hline \multicolumn{2}{|l|}{1.2 Oscillatory } \\
\hline 1.2.1 Low frequency & $0.3-50 \mathrm{~ms}, 0-4 \mathrm{pu}$ \\
\hline 1.2.2 Medium frequency & $20 \mu \mathrm{s}, 0-8 \mathrm{pu}$ \\
\hline 1.2.3 High frequency & $5 \mu \mathrm{s}, 0-4 \mathrm{pu}$ \\
\hline \multicolumn{2}{|l|}{ 2.0 Short-duration variations } \\
\hline \multicolumn{2}{|l|}{ 2.1 Instantaneous } \\
\hline 2.1.1 Interruption & $0.5-30$ cycles, $<0.1 \mathrm{pu}$ \\
\hline 2.1.2 Sag (dip) & $0.5-30$ cycles, $0.1-0.9 \mathrm{pu}$ \\
\hline 2.1.3 Swell & $0.5-30$ cycles, $1.1-1.8 \mathrm{pu}$ \\
\hline \multicolumn{2}{|l|}{ 2.2 Momentary } \\
\hline 2.2.1 Interruption & 30 cycles $-3 \mathrm{~s},<0.1 \mathrm{pu}$ \\
\hline 2.2.2 Sag (dip) & 30 cycles- $3 \mathrm{~s}, 0.1-0.9 \mathrm{pu}$ \\
\hline 2.2.3 Swell & 30 cycles- $3 \mathrm{~s}, 1.1-1.4 \mathrm{pu}$ \\
\hline \multicolumn{2}{|l|}{ 2.3 Temporary } \\
\hline 2.3.1 Interruption & $3 \mathrm{~s}-1 \mathrm{~min},<0.1 \mathrm{pu}$ \\
\hline 2.3.2 Sag (dip) & $3 \mathrm{~s}-1 \mathrm{~min}, 0.1-0.9 \mathrm{pu}$ \\
\hline 2.3.3 Swell & $3 \mathrm{~s}-1 \mathrm{~min}, 1.1-1.2 \mathrm{pu}$ \\
\hline \multicolumn{2}{|l|}{ 3.0 Long-duration variations } \\
\hline 3.1 Interruption, sustained & $>1 \mathrm{~min}, 0.0 \mathrm{pu}$ \\
\hline 3.2 Undervoltages & $>1 \mathrm{~min}, 0.8-0.9 \mathrm{pu}$ \\
\hline 3.3 Overvoltages & $>1 \mathrm{~min}, 1.1-1.2 \mathrm{pu}$ \\
\hline 4.0 Voltage unbalance & Steady state, $0.5-2 \%$ \\
\hline \multicolumn{2}{|l|}{ 5.0 Waveform distortion } \\
\hline $5.1 \mathrm{DC}$ offset & Steady state, $0-0.1 \%$ \\
\hline 5.2 Harmonics & Steady state, $0-20 \%$ \\
\hline 5.3 Interharmonics & Steady state, $0-2 \%$ \\
\hline 5.4 Notching & Steady state, N/A \\
\hline 5.5 Noise & Steady state, $0-1 \%$ \\
\hline 6.0 Voltage fluctuations & Intermittent, $0.1-7 \%$ \\
\hline 7.0 Frequency variations & $<10 \mathrm{~s}, \mathrm{~N} / \mathrm{A}$ \\
\hline
\end{tabular}

averting such problems are increasing [11].

We believe that it is not economically or technically reasonable to require power suppliers to take preventive measures (waveform-level or millisecond-order maintenance of voltage in particular) for particular consumers that use many load devices that are characteristically vulnerable to decreases in power quality to. That is to say, according to the power quality and needs, measures such as installation of an uninterruptible power system (UPS) [12] and optimization of the protection system on the demand side are important from the viewpoint of social cost and overall system optimization. No optimal problem-solving approach has been proposed to deal with the power quality problem, because the causes of the phenomena are complex and diverse. The tendency to occur and frequency of occurrence are not understood, because the tolerance of the load equipment varies by type and class, and because there are no clear standards or criteria for countermeasures. Installation of a UPS is a common measure to maintain power quality, but the known problems include excesses in specifications, system capacity, and battery backup time, and excessive redundancy in power system configuration [13].

\section{Obstacles to Power Quality and Reliability}

The electrical power grids owned and operated by power companies in Japan can provide extremely high supply reliability through redundant and adaptive networks and standby power generation facilities as well as advanced distribution systems. On the other hand, power quality phenomena that cause power outages that halt the function and operation of facilities and equipment or malfunctioning or damage on the consumer side are often caused directly by factors that are external to the electrical power grid, including social activities, weather conditions, and degree of technological development.

Focusing on Japan, we take an overall view of the trends in power interruption and power quality in electrical power grids over recent years in the following sections.

\subsection{Outage Causes and Countermeasures}

According to the Electrical Safety Statistics for Japan [14], power interruptions are broadly classified as accidental power interruptions and planned power interruptions in the following way.

- Accidental power interruption: accidents or damage involving work on electrical facilities of the utilities (except on service drop lines) or the effect of other accidents that cause power interruption to ordinary consumers, but not including cases in which the circuit was automatically reclosed to end the power interruption

- lanned power interruption: planned interruption of power for the purpose of constructing, modifying or maintaining utilities' grids

Accidental power interruptions are further classified as those related to system accidents and local power interruptions. The proportion with which accidents occur in electrical power grids by sector is shown in Fig. 6, where we see that electrical accidents affecting high-voltage distribution line sectors account for $87 \%$ of the total, and most power interruptions are local, with problems only rarely spreading to affect a wide region. In recent years, automation of distribution sectors has advanced [15] and those sectors are configured such that, even when power interruption accidents occur, the problem is isolated at the point of occurrence and power is restored within minutes by automatic switches with minimum harm [16]. That is one factor in the extremely high reliability of power system compared to other countries.

The causes of accidental power interruption in distribution sectors in Japan are shown in Fig. 7. The main causes are natural phenomena (56\%) and accidental contact (12\%), etc. Accidents that are not directly related to power company facilities and operation account for roughly 70\% [17]. 


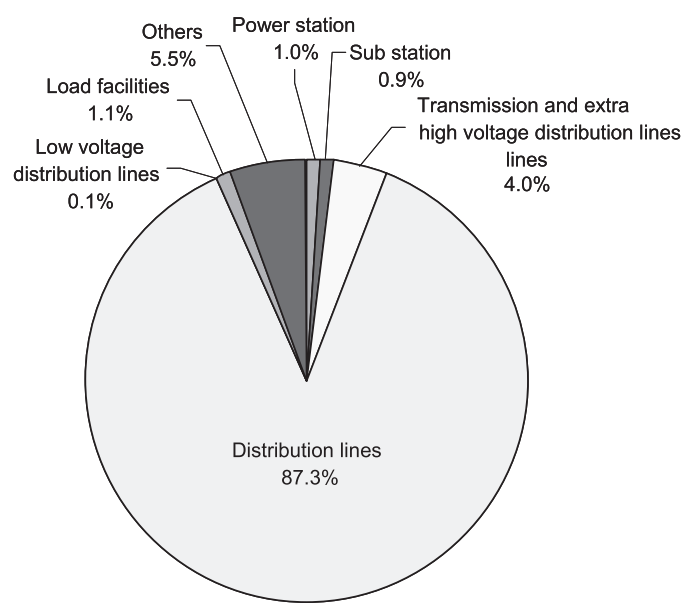

Fig. 6 Ratio of secters of power outages.

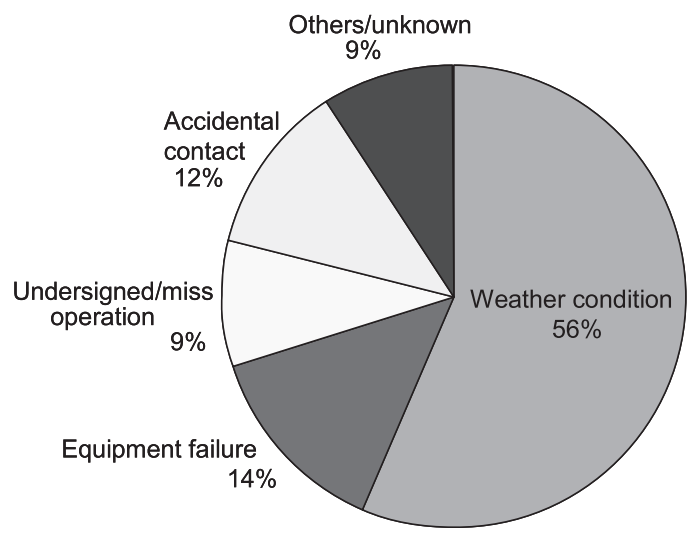

Fig. 7 Root cause of interruptions on distribution lines.

3.2 Wide-Area Interruptions Caused by Natural Disasters, etc.

While local power interruptions are becoming rare, widearea power outages continue to occur with some frequency in Japan and other countries. Japan has experienced major power outages due to natural disasters such as the Great Hanshin Earthquake (1995) [18] and Typhoon $\sharp 21$ in Ibaraki Prefecture (2002) [19] as well as a power transmission line accident involving a crashed Self-defense Force aircraft (1999) [20] and a wide-area outage in the Tokyo area caused by a river-barge crane contacting transmission lines (August 2006) [21], [22].

In other countries, too, there have been power outages accompanying the relaxation of power regulations and equipment failures such as the major outage in Auckland, New Zealand (1998) [23], the California power outages (1998 and 2001)[24], wide-spread power outages in major European cities in England, Italy, and the major power outage in North America (August 2003) [25], [26]. Such outages involving both very large areas and a long time until restoration of power have occurred often.

Electrical power grids are artificial systems for which

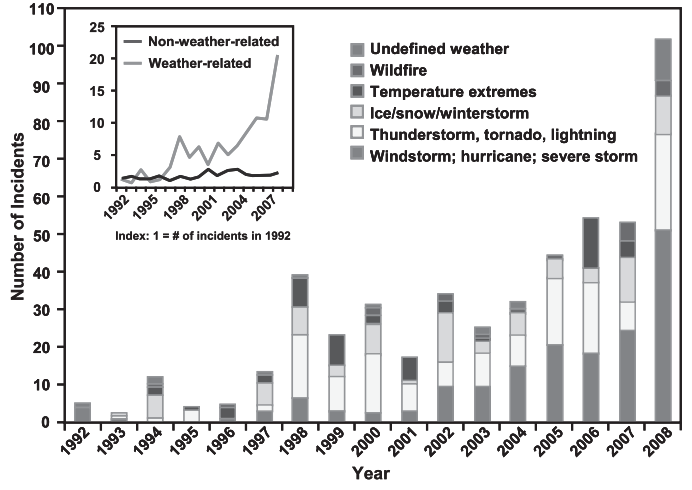

Fig. 8 Significant weather-related U.S. electric grid disturbances.

complete protection against typhoons, earthquakes, lightning and other such phenomena is very difficult. Although these phenomena have extremely low probabilities of occurring, this shows that large-scale power outages caused by natural disasters or man-made problems can occur as well as local outages. Although there is much that is unclear in the cause and effect relationship between natural phenomena and power grid accidents, the relations can be represented statistically.

As an example, the relationship between abnormal weather and grid disruptions in the United States is shown in Fig. 8 [27]. Weather-related disruptions increased by a factor of 20 from 1992 to 2008, and strong winds, abnormally high temperatures, flooding, lightning and other weather phenomena are expected to account for a large proportion of outages in the future as well. Other than weather, there is concern for grid disruptions due to human error and intentional acts, and consumers must always face a risk of power cut-off. Although the frequency is very low, the occurrence of major disasters produce a tremendous amount of damage. An example of the relation between disaster frequency and damage cost is shown in Fig. 8. Disruptions due to major earthquakes or terrorism occur once in a number of decades but can cause damage valued at a billion dollars or more Fig. 9. As the dependence of social life on electric power increases, measures to protect power facilities from such damage become more important, and the efficiency and appropriateness of investment for that purpose have become issues [29].

\subsection{Increase in Distributed Power Systems}

In recent years, the expectation for achieving a sustainable society through the use of renewable energy to protect the global environment and prevent global warming has been rising [30]. The growing awareness of environmental problems and expectations for natural energy, and various other factors such as the implementation of national policies and economic support that reflect international agreements [31] and lower facility costs from technological innovation and manufacturers have resulted in a sharp expansion in the introduction of distributed power systems such as wind gener- 


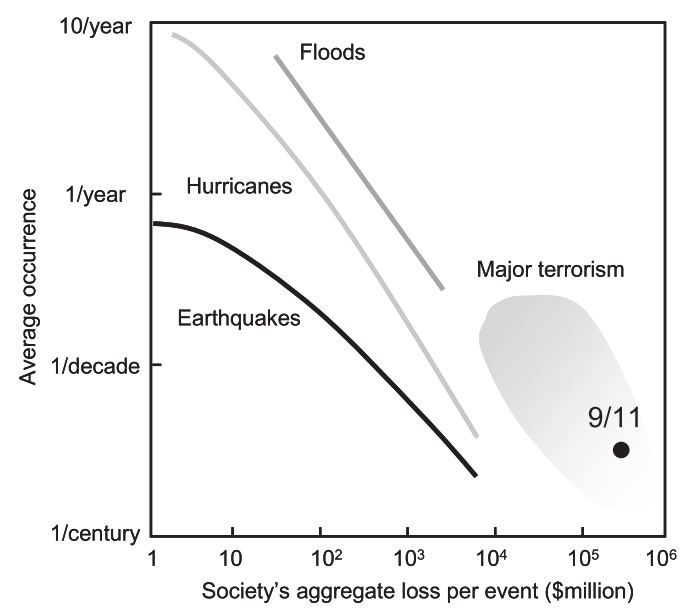

Fig. 9 Society-wide impacts from major disasters.

ators [32] and solar power [33].

Distributed power systems are installed near the demand area, and while they are regarded as effective for control of $\mathrm{CO}_{2}$ emissions and lower transmission loss, they may also cause problems such as voltage surges through reverse flow into the grid [34], [35].

Also, the control of the output of natural energy sources is difficult, and voltage drops where areas connect can cut off the distributed power system from the grid, making the grid unstable and worst-case power outages have been reported [36]-[38].

Many distributed power systems involve mostly consumer assets, and when a power interruption or other such accident occurs on the grid, power continues to be supplied by the distributed power system alone. There is thus a risk of independent operation in which power is supplied locally to the lines of the power company and to the loads of other parties [39].

Furthermore, overcurrent or voltage fluctuation may occur when a distributed power system that is operating independently recloses asynchronously with the grid, not only decreasing power quality, but possibly damaging facilities and equipment of the power company and other consumers.

In Japan, distributed power systems and other environmental facilities that concern the grid are being planned [40], but an appropriate balance for stable power supply and use on both the supplier side and the consumer side is required, because introducing distributed power systems that use natural energy sources to the existing grid brings the risk of affecting power quality and supply reliability.

\section{Trends and Problems in the Introduction of Infor- mation and Communication Systems}

Our dependence on ICT systems in our daily lives has increased in recent years. Although it has escaped our deep awareness, the role of ICT has become as important as electricity, gas, water, traffic, communication, and other important elements of social infrastructure. The provision of di-

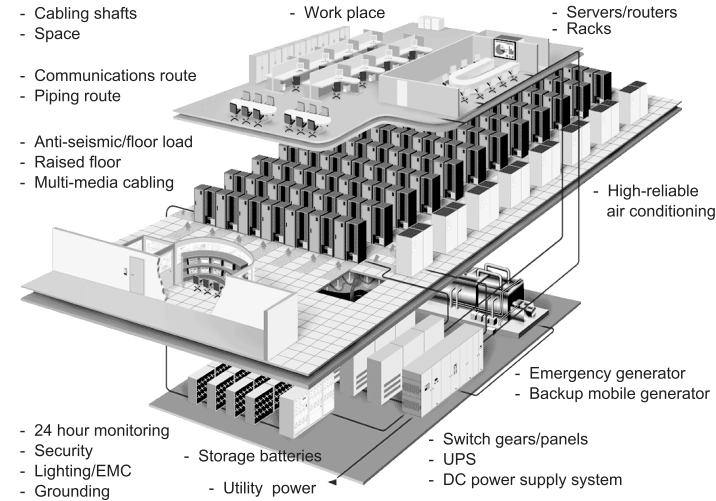

Fig. 10 Typical layout of data center

verse, uninterrupted services via ICT systems supports economic growth, promotion of the common wealth, prosperity, and a safe and secure life, and is essential to the continuing development of society.

Data centers are special ICT buildings and facilities that support such services, and the number of data centers, including new construction, has increased sharply in developing countries and regions as well as in advanced countries and regions such as Japan, Europe and North America. The rapid expansion in use of ICT via data centers has brought with it an increase in energy consumption in that field, and the effects on the existing power grid, global environment and resources, and social life are steadily increasing.

The trend in the introduction of ICT systems and the effects of that trend are summarized below.

\subsection{Social Effects of Introducing and Expanding Data Centers}

Formerly these facilities were called 'computer centers', but communication networks became faster and increased in bandwidth and became more interconnected, and the term 'data centers' has been the most common term used since the late 1990s.

Currently, the term 'data center' generally refers to ICT-related facilities or to a form of business. As we can see from the example data center configuration shown in Fig. 10, data centers are facilities in which servers and computers, data storage devices and media as well as network equipment for communication and data exchange with the outside are centrally housed in sturdy buildings that are equipped for resistance to power interruption, fires, earthquakes, flooding, and other such threats [41].

Data centers can also be said to be large industrial facilities that are information factories for data processing and handling [42]. Within data centers, a large amount of ICT equipment is operated to provide various services for businesses and individuals. The ICT equipment itself comprises microprocessors, memory devices and digital electronic circuits, which do not tolerate even slight drops in voltage, to say nothing of actual power outages. Although it depends 
on the configuration of the ICT equipment, a high quality power supply is required for stable operation with no malfunctioning of the ICT systems. Accordingly, a power system that provides a stable supply of reliable and quality power is essential to realizing the potential of ICT to achieve advanced and prosperous lives in society [43].

\subsection{Energy Consumption in Data Centers}

Data centers consume a large amount of energy and in nearly all cases at this time, they receive and use the power generated by power companies and transmitted via distribution facilities. Because of integration and centralization, the amount of power received by data centers has increased from previous levels of a few megawatts to, in some cases, over $10 \mathrm{MW}$

In the United States, the power transmission network is aging and the transmission capacity is limited, and reports of data centers being constructed near power plants to shortcut the distribution system are increasing [44], [45]. The location constraints imposed by securing an adequate supply of power that is inexpensive and stable is another problem facing future construction of data centers. Estimates of future power consumption by data centers on the macroscopic level are being made by Japan [46], [47] and various other countries and organizations [48], [49].

One such study calculates that ICT will account for from 15 to $20 \%$ of Japan's domestic power demand in 2025 [46]. According to those calculations, the increase in power consumption by Japan's data centers from 2006 (21 billion $\mathrm{kWh}$ ) to 2025 (52 billion $\mathrm{kWh}$ ) will be 31.3 billion $\mathrm{kWh}$. If that amount of power were to be supplied by power plants with a rated output of one million kilowatts for example, it would require construction of four new power generation units (assuming an annual total of $8760 \mathrm{~h}$, up-time ratio of 0.8 , and annual production of 7 billion $\mathrm{kWh}$ ). Data centers in Japan that consume an amount of energy converted to a fuel oil basis of $1,500 \mathrm{k} \ell$ or more are classified as 'factories specified for energy management' under laws for the rationalization of energy use (Energy Conservation Law) [50] and are thus required to set a target for reduced energy use and establish a plan for achieving the target. That fact, too, makes greater efficiency and energy conservation urgent problems for data centers and is of high concern to everyone involved in data center construction and operation.

\subsection{Heat Density in Data Centers}

In the ICT field, the performance of CPUs (Central Processing Units) and other processors for processing high definition images and video and large volumes of data at high speed is increasing daily. In the field of communications, the transition from the conventional network of switches, transmission equipment and wireless equipment to the NGN (Next Generation Network), which uses routers and servers, is proceeding [51]. That, too, is affected by the problem of energy consumption in the processing of communication
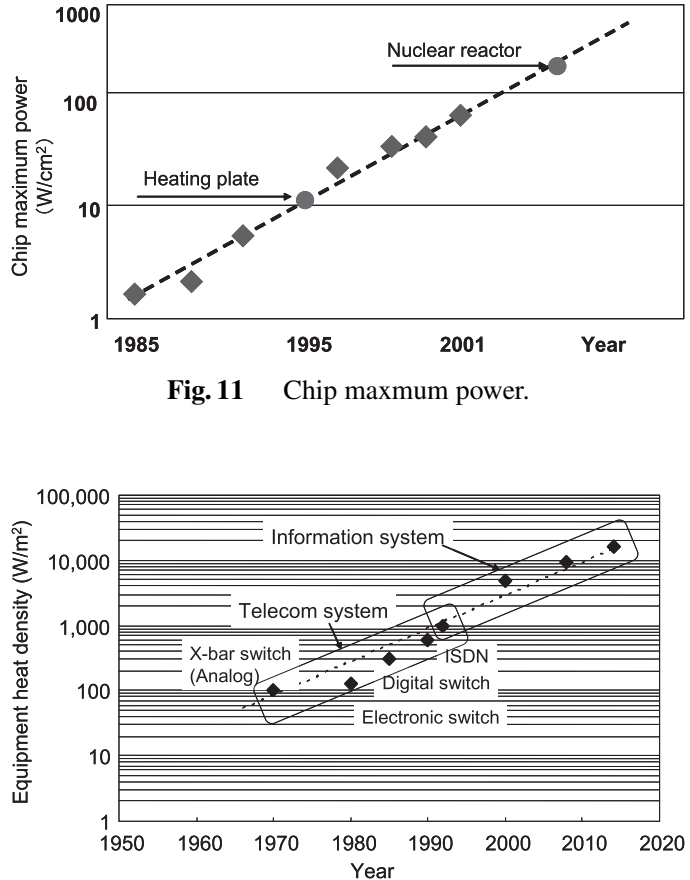

Fig. 12 ICT equipment heat density.

traffic that is increasing yearly [52], [53].

As shown in Fig. 11, the amount of heat per unit area generated by processors exceeded that of irons and hotplates (from several watts to $10 \mathrm{~W} / \mathrm{cm}^{2}$ ) in the $1990 \mathrm{~s}$, and after 2005 it has been said to have reached the heat density of atomic reactors (several hundreds of watts per square centimeter) [54]. The trend in the heat density of communication equipment [55], and equipment for data centers [56] is shown in Fig. 12. Because ICT equipment is equipped with multiple processors at higher mounting density and more ICT equipment is being mounted on data center racks, the annual growth in heat density exceeds the efforts by manufacturers to reduce energy consumption. The heat density of some types of ICT equipment that has been introduced and operated in recent years exceeds $10 \mathrm{~kW} / \mathrm{m}^{2}$, and that value is expected to increase further in the future. The load density for an ordinary office is from 50 to $150 \mathrm{~W} / \mathrm{m}^{2}$, so the heat density in data centers is a special technical problem for which technical countermeasures are being developed.

\subsection{Energy Flow in Data Centers and Measures for Im- provement}

The general power flow to a data center [42] is illustrated in Fig. 13. Taking the primary unit of energy output for power plants to be 1 , about $2 / 3$ is lost in the process of power generation and distribution and only about $1 / 3$ reaches the data center. Although the main load in a data center comprises the servers and other ICT equipment, the total load has three components when we add the air conditioning system and UPS. Currently, the power consumed by ICT equipment in data centers is half or less of the power received. Further- 
more, of the ICT equipment, if we exclude the power used by the power supplies and cooling fans for the servers, the power consumption of the processors and memory devices accounts for less than $10 \%$ of the primary power generated.

Beyond reducing power consumption by processors and memory devices, a good balance among the three components of total energy use in the operation of data centers and efficient operation are important for energy conservation data centers and for the prevention of global warming and efficient use of various resources. An example of measures to improve data center efficiency and energy conservation is presented in Fig. 14 [42].

The number of data centers that are introducing distributed power systems for environmentally-friendly operation is increasing. For example, the introduction of a solar power system to offices by Google in the United States involves $1.6 \mathrm{MW}$ solar panels, the largest in the U.S., to achieve a $30 \%$ reduction in power consumption. Similarly, there are many examples data centers in Japan, are also installing solar panels to reduce $\mathrm{CO}_{2}$ emissions as a measure against environmental problems. In Europe, a number of data center construction projects that use wind-generated power in areas where wind conditions are suitable have been announced.

There is also a movement to locate large integrated and centralized data centers near power plants outside the city and plans to operate data centers on geothermal power. To deal with power transmission and improvement of energy efficiency, and to deal with environmental problems, examples of data centers that are introducing distributed power systems are increasing in proportion to the expansion of ICT use.

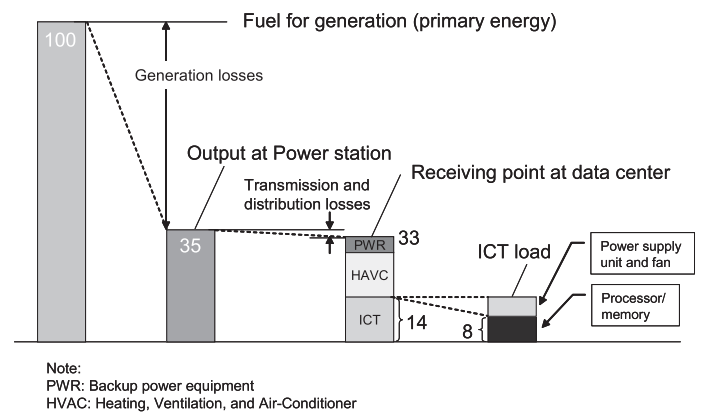

Fig. 13 Power flow from power station to ICT equipment in data center.

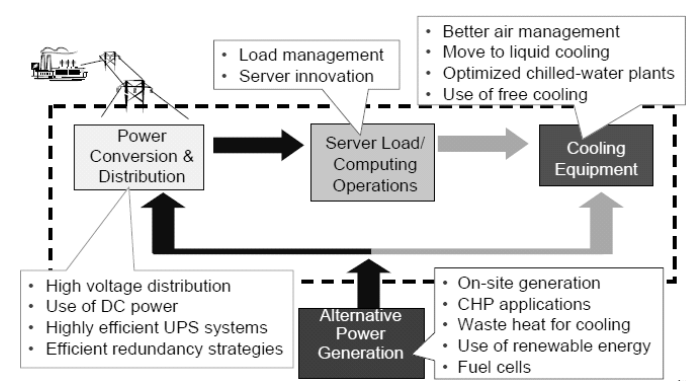

Fig. 14 Improvement methods for data center's energy efficiency [42].

\section{Requirements for Highly-Reliable Power for Miss- ion-Critical Facilities}

Data centers and other ICT-related facilities are required to operate continuously 24 hours per day and 365 days per year without interruption of services. In the telecommunications industry, communications buildings are equipped with highly reliable power supply systems [57] that use appropriate combinations of the commercial grid, long-life storage batteries, emergency generators and other such facilities. Companies have also been attempting their own measures to maintain high reliability in the face of natural disasters that have occurred with increased frequency and scale in recent years and various other risks [58], [59].

Now that ICT systems have become a part of the social infrastructure, the effects of ICT system failures can be assumed to include threat to life and property as well as economic loss. Accordingly, in addition to high energy efficiency and energy conservation, the stable supply of highquality power to ICT system is also essential to safe and secure living in society. The economic cost per hour of loss of business due to ICT system down-time, etc. can be calculated, and an example is presented in Table 2 [60]. Many phenomena related to power quality, and surge over-voltage and voltage dips in particular, are of short duration, mostly in the range from microseconds to a few cycles. For load equipment and facilities that have insufficient tolerance to fluctuations in input, however, those phenomena may cause malfunction or system failure. Even a single power quality problem often requires hours to restore normal operation [61]. The cost per downtime event for various industries is presented in Table 3 [60].

Depending on the conditions, ICT system failure may cause a huge economic loss, and as dependence on ICT systems increases into the future, the effects of failures is

Table 2 Cost of downtime per hour [60]

\begin{tabular}{lc}
\hline Industry & Average Cost per Hour (US\$) \\
\hline Brokerage & $6,400,000$ \\
Energy & $2,800,000$ \\
Credit card operations & $2,600,000$ \\
Telecommunications & $2,000,000$ \\
Manufacturing & $1,600,000$ \\
Retail & $1,100,000$ \\
Health care & 640,000 \\
Media & 340,000 \\
Human life & "Priceless" \\
\hline
\end{tabular}

Table 3 Cost of downtime per event [60].

\begin{tabular}{lc}
\hline Industry & Typical Loss (US\$) \\
\hline Financial & $6,000,000 /$ event \\
Semi-conductor manufacturing & $3,800,000 /$ event \\
Computer & $750,000 /$ event \\
Steel/heavy manufacturing & $300,000 /$ event \\
Telecommunications & $30,000 /$ event \\
Data processing & $10,000 /$ event \\
Plastics manufacturing & $10,000 /$ event \\
\hline
\end{tabular}


expected to be even greater than has been experienced so far. In Europe, North America, and some other countries as well as in Japan, various methods that enable a shift from the present complete dependence on the existing large-scale grid for power to simultaneous supply of power and heat in areas that are near the demand are being studied. In the background of these studies are needs that are diverse and nonuniform, such as transforming the power industry, improving the performance of small and medium scale power generators and facilities, promoting the use of low-cost, renewable energy, and improving the reliability of the power grid, but the research has a common direction, which is an ideal new energy grid that is oriented to the future. On the part of power consumers, systems for ICT and diverse other fields that include medicine, finance, transportation, manufacturing, etc., there is increasing need for highly reliable power, such as higher quality of grid power and uninterruptable power supply, etc. [60].

The expansion in use of digital load devices in recent years has resulted in a diversification of needs with respect to power, including many individual consumers feeling the need for high-quality power supply in addition to businesses that use ICT systems, and a certain proportion of consumers who wish for lower charges with the previous degree of power quality [62], [63]. In conventional power systems, reliability and quality are standard items and there is no room for consumer choice. In recent years, however, appropriate combination of power equipment that uses power electronics, distributed power systems, and storage batteries have made it possible to simultaneously offer multiple grades of power quality to satisfy diverse needs. A new concept of the power network or power grid for implementing that scenario was created and much research and testing is being done in that area [64]-[66].

In the following sections, we explain typical power schemes that are under research.

\subsection{Microgrids}

The concept of the microgrid has been proposed [67], [68]. A microgrid comprises many small distributed power systems that can be operated together autonomously as a local system without dependence on existing grid power. The power source facilities that constitute a microgrid are mainly distributed systems that have a small capacity compared to the existing ultility's grid (See Fig. 15). Distributed power systems often include types of systems that operate intermittently and have unstable output, such and wind power and solar panels, so it is difficult to maintain a balance of supply by using such systems alone. Achieving stable microgrid operation requires study of control systems and energy storage facilities [69]. There is no clear definition of a microgrid, but an example is "a small-scale grid that has a distributed power system and load that involves on-site powergeneration and supply systems that have multiple power sources and heat sources that can be controlled and managed together using ICT-related technology, and can operate inde-

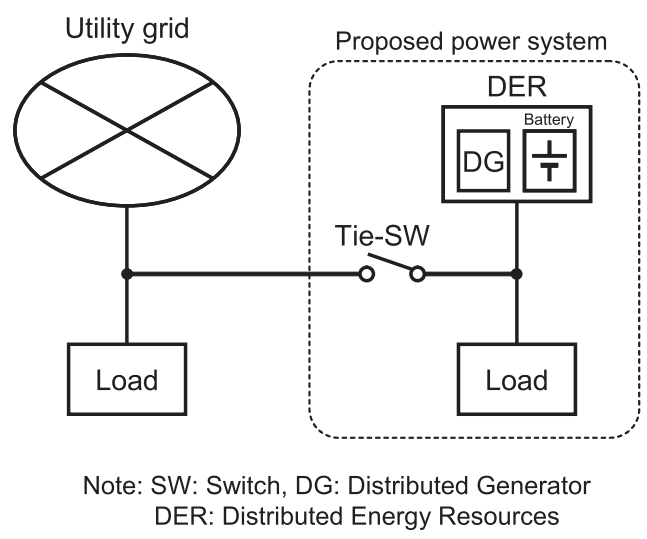

Fig. 15 Typical configuration of microgrid.

pendently of the commercial power grid" [70]. Microgrids are expected to serve as local integrated energy systems that are more efficient and functional [71].

\subsection{Smartgrids}

The smart grid is being actively studied in many countries as a new concept in power systems whereby ICT is used to raise reliability and power quality, improve the availability of power systems, increase energy efficiency, introduce and expand the use of renewable energy, and reduce peak load [72]. In contrast to a microgrid whose capacity and scale and target area are limited compared to existing power systems, the smart grid is a concept that includes all types of power generation, power transmission and distribution, and power customers while accommodating future developments like distributed power supplies and electric vehicles whose introduction and expansion are expected. The purpose and necessity of researching smart grids differ from one country to the next.

In Japan, the future introduction of renewable energy on a large scale would call for a Japanese type of smart grid that could cope with the unstable output of this type of energy. This smart grid would consist of technology for effectively using and controlling power-electronics equipment and storage facilities including electric vehicles. It would also cooperate with the existing power system to prevent jumps in distribution-line voltage and deterioration in power-supply reliability and power quality [73], [74].

In the United States, cooperative operation between the power system and telecom sites as load facilities is being studied in the form of demonstration projects for reducing peak load. A typical power-system configuration of a telecom site is shown in Fig. 16. The DC load at a telecom site includes switching equipment, transmission equipment, and radio equipment that makes up most of the equipment in the facility, but there is also an AC load consisting of lighting equipment, air conditioning equipment, and some information devices. As shown in the figure, applications in this field are achieved through power converters, a battery system, standby generators (including distributed power sup- 


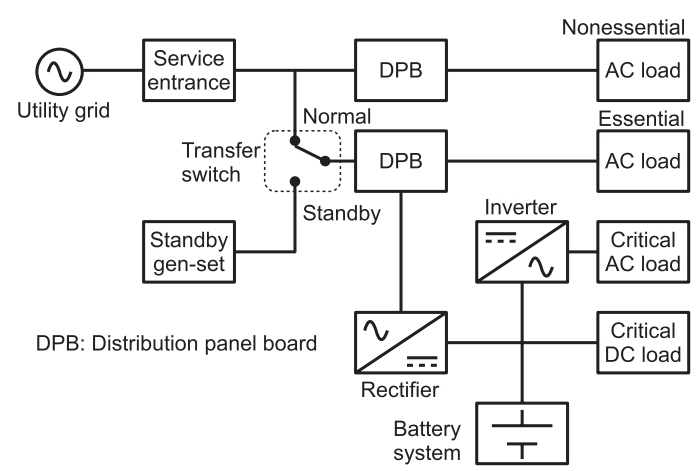

Fig. 16 Telecom power system for smart grid demonstration.

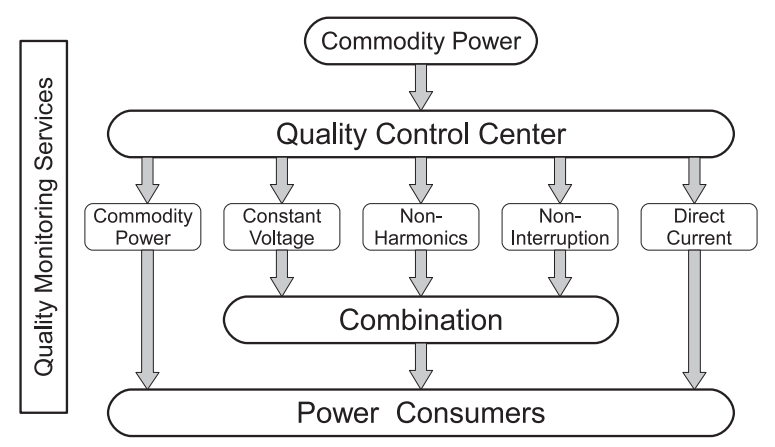

Fig. 17 Concept of FRIENDS.

plies), control, monitoring, and protection equipment, and DC loads that are operated on a 24/365 basis. These are essential constituent elements of a smart energy system that has been much discussed in recent years. As one type of DC power supply, the battery system shown in the figure enables power to be supplied without interruption even if AC input should be shut down or switched. It can also be used to reduce peak load without bringing the load system to a halt.

In New York City, a project has begun on demonstrating the interoperability of demand response centered about the power system and 29 telecom sites with the aim of reducing peak load. The plan here is to evaluate not only the use of standby generators and battery systems but also the integration of fuel cells and wind facilities during the course of the project [75].

\subsection{FRIENDS}

In preparation for deregulation in the electrical industry, FRIENDS (Flexible Reliable and Intelligent Electrical eNergy Delivery System), has been proposed [76], [77] as a new electric power delivery system that enables the installation of small-scale distributed power systems and energy storage systems on the consumer side, power retail distributing, and flexible setup of consignment power lines to meet various consumer requirements (See Fig. 17).

FRIENDS includes the concept of multiple-quality power supply in which there is no power interruption, voltage dips, or high harmonics, etc., as well as the provision

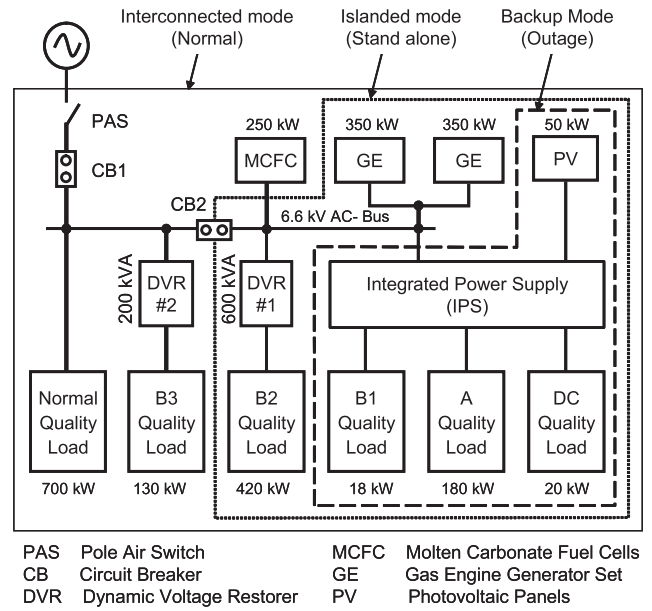

Fig. 18 Configuration of the MPQSS installed in Sendai.

of low-cost power. The studies of FRIENDS address business operation issues as well as technical issues such as optimum operation of small-scale generation facilities and energy storage systems, advanced distribution systems, power quality and demand management, automated metering and customer information services, etc. [78]-[80].

\subsection{Multiple Power Quality Supply Systems}

As an example of the development a new electric power delivery system that is typical of FRIENDS, the Multiple Power Quality Supply System scheme is being investigated. After various proposals and laboratory investigations, the Agency for Natural Resources and Energy of the Ministry of Economy, Trade and Industry commissioned construction of a specific power network system under the concept of "The Future Power Network System" in 2002, and the New Power Network System Association was established for that purpose.

As part of that work, verification through simulations related to the direction for specific systems that will be required in the future and studies on the direction for specific future technical development with the objective of coordinating grid power and distributed power have begun.

Through those discussions, a future image of the new power network system was presented, the Multiple Power Quality Supply System (MPQSS) and integrated control system was evaluated on the basis of simulations, and the technical development issues were summarized [81].

Then, in response to a call by New Energy and Industrial Technology Development Organization (NEDO), field operation of the Multiple Power Quality Supply System [82] was conducted in Sendai City in the four years beginning with 2003 [83].

Figure 18 shows the configuration of the MPQSS installed in Sendai for demonstration. One MPQSS study raised the issue that although DC distribution is expected to reduce the cost of power interruptions, calculating and evaluating the cost from an overall view of the entire system 
is problematic [84].

In MPQSS, the power-supply range (the arrangement of load-demand facilities) is about $1 \mathrm{~km}$ square, which necessitates the deployment of optical fiber for the trunk line. To control the supply of power and compensate for drops in power quality, various types of data are simultaneously measured at 22 points including the amount of power generated, load demand, and voltage and current waveforms at distributed power supplies. These data are passed to the operations-control equipment of the same power-supply system for use in operations. Installing a GPS device at each of these points enables time synchronization so that data from many points can be simultaneously analyzed [85].

The Great East Japan Earthquake, which stuck at 2:46 in the afternoon of March 11, 2011, coupled with the subsequent tsunami and nuclear accident at the Fukushima No. 1 nuclear power plant, inflected massive damage in the eastern part of Japan. As a result of this disaster, a long-term power outage of about two and a half days occurred even in Sendai city where multiple power quality supply systems had been operating. At the same time, the trunk line for mediumpressure gas was undamaged and gas-supply services were never interrupted in the city. As a result, gas-engine power generators, though experiencing a momentary shut down as soon as the city lost power, could be restarted shortly thereafter by personnel in charge so that power could be supplied to university hospitals and welfare facilities and the supply of heat using thermal exhaust from power generation could be continued. Additionally, the supply of high-quality power such as DC and uninterruptible AC to loads continued without interruption even immediately after power was lost. These examples demonstrate the effectiveness of this system in the face of major disasters.

Furthermore, a demonstration of the Premium Power Quality Park, which has a concept similar to MPQSS, for factories has been reported in the United States [86].

\subsection{Cost-Benefit Analysis of Multiple Power Quality Sup- ply Systems}

If the quality of supplied power comes in many types, the analysis models and calculations become complicated making studies difficult to perform. Reference [87], however, has reported case studies on the cost-benefit analysis of systems each consisting of an uninterruptible AC power supply and an uninterruptible DC power supply. Considering the potential effectiveness (advantage) of using a highreliability power supply to prevent losses due to power outages or accidents, these studies assessed the validity of constructing three such systems on the basis of net present value (NPV) taking into account initial investment, running costs, and expected losses as calculated from the probability of accident occurrence.

Figure 19 shows the model used here for evaluating the cost benefit of three cases: 1) multiple power quality supply system (10 kW each for AC and DC), 2) a multiple power quality supply system with a $20 \mathrm{~kW}$ photovoltaic generator

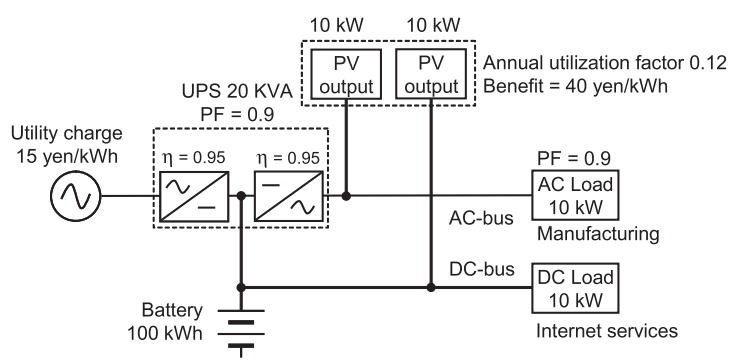

Fig. 19 Cost-analsys model of mutiple power qualty supply system.

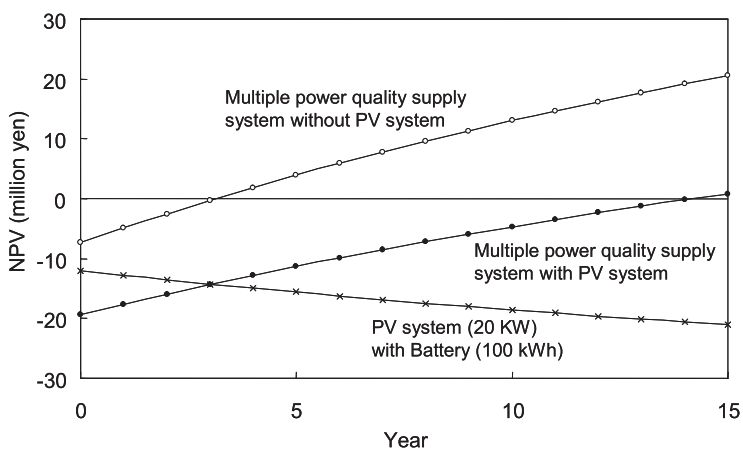

Fig. 20 Estimation result of NPV for power backup equipment of three cases: Multiple power quality supply system without PV system, Multiple power quality supply system with PV system, and PV system with battery.

(10 kW each for AC and DC use), and 3) a $20 \mathrm{~kW}$ photovoltaic generator $(10 \mathrm{~kW}$ each for $\mathrm{AC}$ and $\mathrm{DC}$ use) combined with a $100 \mathrm{kWh}$ battery for control of power-supply fluctuations. The load applications of AC and DC are manufacturing and Internet services, respectively, each with a load capacity of $10 \mathrm{~kW}$. An AC power supply is applied to manufacturing applications to provide backup for semiconductor manufacturing equipment, motors, etc. A DC power supply is applied to Internet services considering the ease of driving ICT equipment like servers and telecommunication devices by DC and the fact that high-efficiency operations can be performed with DC. A load system that shuts down due to a problem in the power supply system would normally take about $2 \mathrm{~h}$ to recover for both DC and AC applications.

Results of calculating NPV for the above three cases are shown in Fig. 20. For the case of a photovoltaic generator combined with a battery for controlling power-supply fluctuations, NPV never becomes positive for the expected lifetime of the facilities with the result that facility investment cannot be recovered. However, when combining that system with a multiple power quality supply system, results indicate the possibility of obtaining a backup power supply that can be effective (advantageous) in preventing power outages or other interruptions to a load system and that can recover facility investment within the 15 years of facility lifetime. 


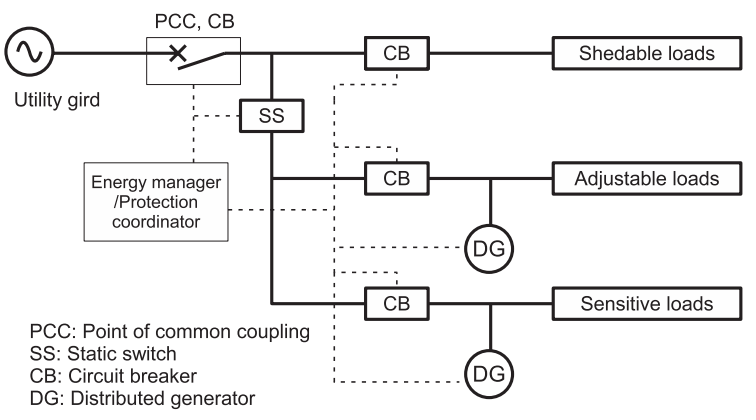

Fig. 21 Typical configuration of CERTS's microgrid.

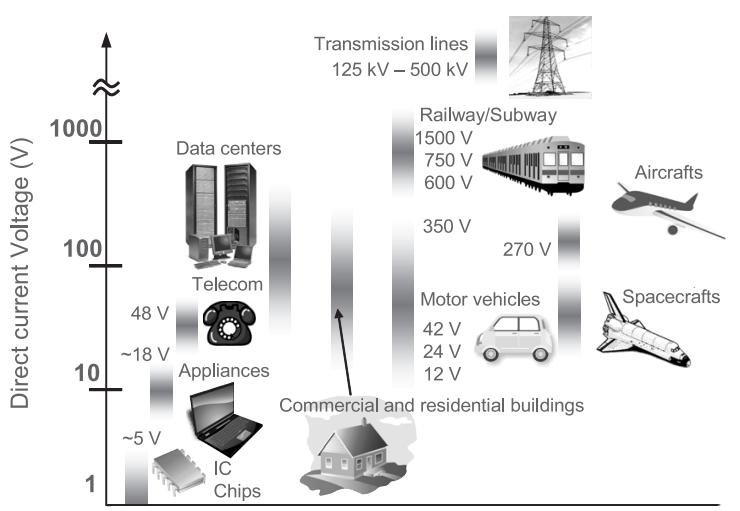

Fig. 22 Today's DC power applications.

\subsection{CERTS}

In the United States, studies of a power supply system in which multiple levels of power quality are provided in accordance with the demand of the load system began in response to the major power outage in North America that occurred in 2003 [88].

The U.S. Department of Energy (DOE) is leading the field in support for microgrid development, and the Consortium for Electric Reliability Technology Solutions (CERTS) has been formed of members from government, academia and commerce, including the Lawrence Berkeley National Laboratories, the University of Wisconsin, the American Electric Power company among others. Various proposals have been made and testing has been conducted by the consortium [89]. The concept of applying supply reliability and quality differently according to the importance of the load when power outages or facility failures occur, or when constraints on power source operation restrict supply capacity, is also being introduced by CERTS, and is similar in concept to FRIENDS and MPQSS.

The microgrid being studied by CERTS (See Fig. 21) is intended to shift with continuity to independent operation when there is an interruption of grid power or the supplied power is insufficient, and then reconnect to the grid when grid power is restored. Thus, methods for automatic and seamless switching between being connected to the grid and independent operation, methods for protection against short circuit failures during independent operation, and microgrid control methods for stability of voltage and frequency under the conditions of independent operation, etc. are being tested [90].

\section{DC Power Supply Systems}

The ordinary power provided by power companies and others in the electricity industry is alternating current at a frequency of $50 \mathrm{~Hz}$ or $60 \mathrm{~Hz}$. On the power consumption side, on the other hand, AV equipment, information and communication equipment and other such digital electronic equipment as well as appliances that ultimately operate on direct current or direct current converted from alternating current, such as inverter-equipped air conditioners and refrigerators, have been increasing in recent years [91].

Also, the application range of DC power supplies, such as the growth in introduction of renewable energy sources like solar cells and storage batteries to eliminate the fluctuations in the output of such sources, has expanded rapidly in recent years [92]-[94].

The ICT industry has the same energy requirements as other industries, economy and high operability, but it has the following three additional requirements, all of which must be satisfied simultaneously.

- Low loss and high efficiency

- Supply to high-density loads

- High power quality and reliability

Telecommunications facilities have long used rectifiers in DC power supplies. For data centers, too, DC supply methods are attracting attention in studies of power supply in Europe, North America, Japan and other countries [95][97]. Currently, many data centers are equipped with UPS as a measure against power supply problems, but because ordinary UPS use batteries for energy storage, they require ac-dc and dc-ac power converters that create power conversion loss during normal operation as well as in the back-up operation.

DC supply systems involve fewer stages of power conversion than do AC supply systems, and thus provide the advantage of higher energy efficiency. They also feature higher reliability through simpler configuration [98].

Furthermore, the ease of installing distributed power systems that have DC output near the load facilities and the high connectability and compatibility with battery storage systems and ICT equipment make DC supply systems the subject of much research [99]-[103].

\subsection{Today's DC Power Application}

There are many DC power applications in our daily life and industries. Figure 22 shows some examples of DC power's current uses [104]. Voltage ranges of the applications take on a wide range of values, from hundreds of kilo-volts to less than one volt. For example, HVDC systems are used for 
long energy transmission lines from distant generating stations or for interconnection of separate alternating-current systems. Additionally, low voltages are applied to many digital appliances, like TV sets, personal computers, and so on. Railways are also powered by DC, and automobiles also have DC circuits within them.

\subsubsection{Edison's Invention}

In the early stages of the business of electric power distribution, DC power was set up as the default system for the United States by Edison's invention of an electric distribution system [105]. DC power worked very well with incandescent lamps, which were the daily lighting load. DC power systems could be directly used with lead-acid batteries, which provided valuable load leveling and backup power during DC generator failure. In those days, one of advantages for DC power systems was already achieved by batteries used to store electrical energy, which are still studied by many engineers and researchers today.

DC power plants could be simply paralleled, enabling economical operation by using smaller gen-set and improving reliability. At the introduction of Edison's system, no practical AC motor was available. These were all significant technical advantages for DC power in 1880s. In the "Current war" in the late 1880s, Edison ended up a loser due to AC advantages like the poly-phase system and transformers developed by Nikola Tesla and Lucien Gaulard. In New York City, by 2006 barely more than 50 customers still used the DC service from the city's utility company, and the last direct-current distribution service was shut down in November 2007 [106].

Some cities continued their DC power networks well into the 20th century. For example, Stockholm had a DC network until the late 1970s [107]. Swedish utilities used \pm 220 volts DC for three-wire distribution nominal voltage to deliver electrical power from a DC power station.

\subsubsection{Telecom Power System}

It was recorded that in 1876 Alexander Graham Bell invented the "electrical speech machine" [108] that we today call a telephone. For more than 100 years, telecom power systems have been developed on the basis of direct current technologies, and the telecom business continues to grow all over the world. The basic requirements for a telecommunications power system are to provide uninterruptible power to mission critical loads, to be safe for workers and the public, and to have a lifespan longer than 20 years with maintenance. To meet these requirements, DC power systems have been used in telecommunications power systems all over the world for a long time. The most common operating voltage is 48 Volts $\mathrm{dc}(\mathrm{Vdc})$. Telecommunications power systems are used in many types of buildings, areas, and countries. Figure 23 shows a typical power configuration of the modern telecommunications system.

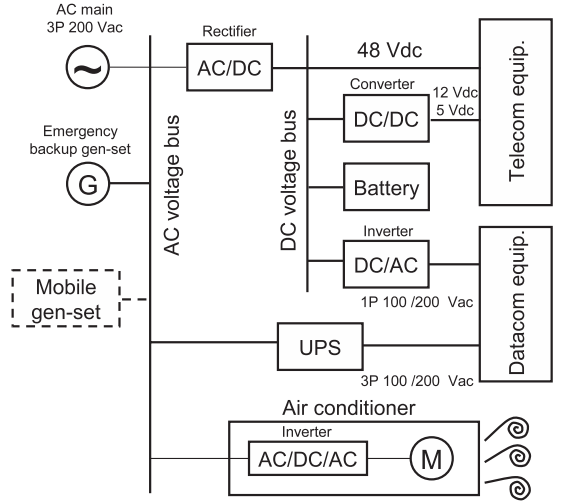

Fig. 23 Typical telecommunication's power system.

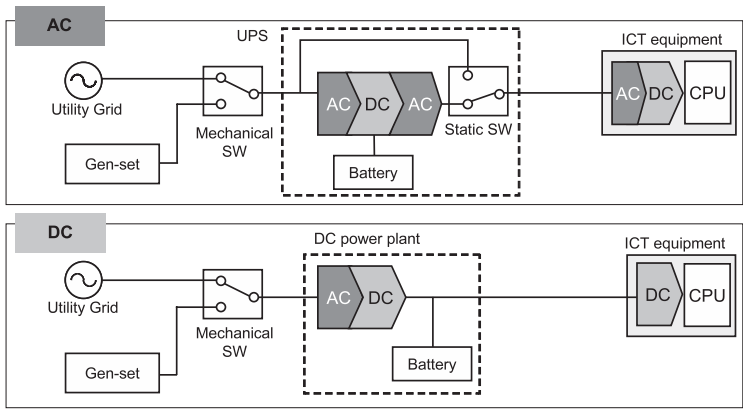

Fig. 24 Comparison between DC and AC power systems.

\subsubsection{New Requirements for DC Powering}

In recent years, ICT systems have been consuming energy increasingly rapidly all over the world. Furthermore, societal trends and interest in 'green' and 'sustainable' technologies have meant increased attention on data centers. In modern data centers, AC systems have generally been the power sources for ICT equipment such as servers, data storage equipment, and network switches; here AC power is converted into DC in the equipment. A past feasibility study in Sweden [109] and US DC demonstrations [110], [111] showed that by supplying DC power directly to the servers, the conversion loss from AC to DC is eliminated, thus improving power efficiency and reducing power consumption (See Fig. 24).

In addition to that, DC at a higher voltage than $48 \mathrm{Vdc}$ leads to reducing green-house gases, which helps to realize an environmental friendly power supply system for ICT equipment. Furthermore, compared with the AC uninterruptible power supply (UPS) system, this DC power supply system has the advantage of a lower failure rate due to eliminating the power conversion unit, thus assuring higher reliability. This system's technology is now attracting worldwide attention. On the basis of the data obtained in this operational test, some candidates across many industries will standardize the higher voltage DC power supply system and extend this system onto the market. 


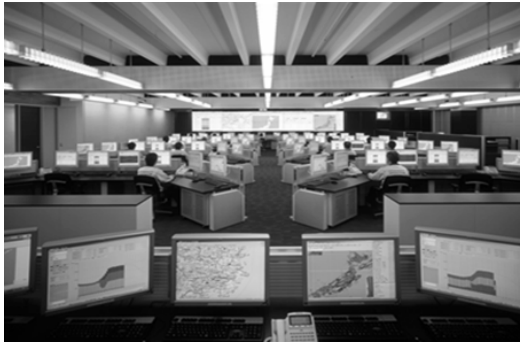

(a) Operation room

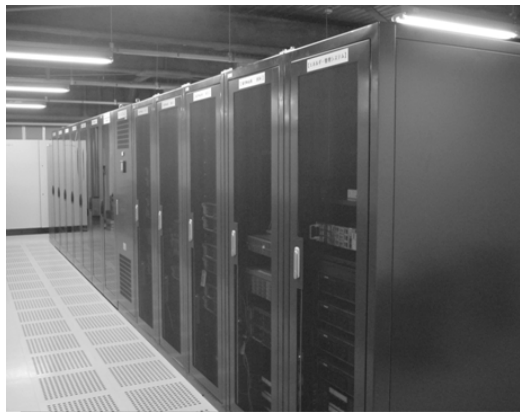

(b) Server room powered by $48 \mathrm{Vdc}$

Fig. 25 NTT Facilties' operation center powered by $48 \mathrm{Vdc}$.

\subsubsection{Expanded Applications of 380 VDC Distribution}

There are big opportunities to replace the present AC UPS systems by introducing a $350 \mathrm{Vdc}$ powering system in not only telecom switch facilities but also commercial buildings and residential homes. In 2006, a Swedish company, UPN, started feeding $350 \mathrm{Vdc}$ into factory buildings, local government offices, broadcasting sites, and so on [112]. The ICT equipment is working very well without trouble. Moreover, $350 \mathrm{Vdc}$ powers PCs, monitors and some types of appliances even though they have no special DC specifications nor have they been modified or redesigned.

\subsection{Some Examples of DC Powering by NTT Group}

\subsubsection{DC-48 V Data Center in Saitama City}

An integrated system that manages and remotely monitors telecommunications power plants has been developed that started operations at the end of 2006 [113] (see Fig. 25). The system is used to operate and maintain more than 200,000 telecommunication power plants, including devices such as rectifiers, inverters, and UPSs, and air-conditioning plants installed in about 8,000 telecommunication buildings. Adapting the entire center system to a $48 \mathrm{Vdc}$ power supply and introducing mutual substituting functions have made the system even more reliable. The configuration of the DC power system is the same as that shown in Fig. 23.

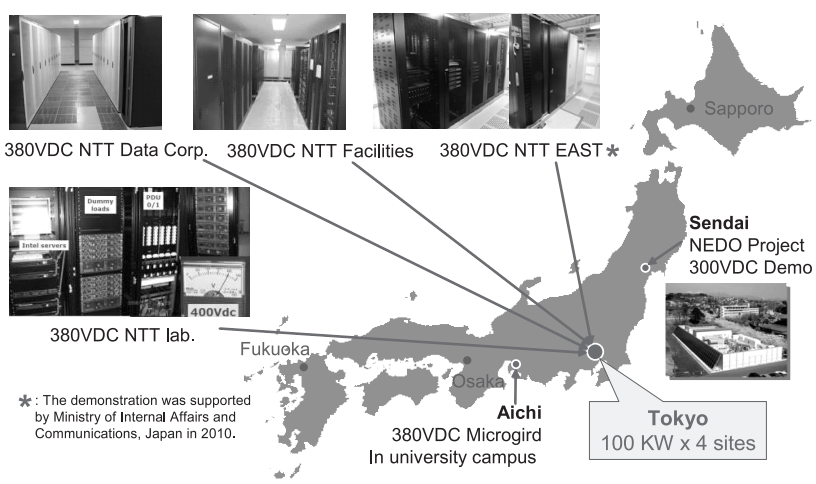

Fig. 26 Recent DC power demonstrations with NTT group.

\subsubsection{Demonstration of Multiple Power Quality Supply System}

NTT Facilities started the first field demonstration of multiple power quality supply system in Sendai, Japan (see Fig. 26) [83]. This demonstration project is entrusted by NEDO. For the study, a multiple power quality supply system that feeds both $\mathrm{AC}$ power and high voltage $\mathrm{DC}$ was built and installed in the field. The project is an interesting approach to provide different power quality levels to different types of customers. The power system could provide higher quality power and improve reliability to meet different customers'needs.

6.3 Development of New Power System for Telecommuncations Sites/Data Centers

Many countries forecast that the amount of energy consumption in data centers will rocket due to ICT applications rapidly progressing and being utilized in societies and industries. For example, the Japanese Ministry of Economy, Trade, and Industry (METI) estimates that the IT sector will be responsible for 15 to $20 \%$ of all electricity consumption in Japan by 2025 . Therefore, a green IT initiative was launched in 2007 to develop effective products in order to cut energy usage in the future IT services.

NTT group companies also started some activities, including new DC power system development, demonstration tests, DC power promotion, and international standardization. In June 2008, NTT holdings officially announced that NTT group companies will introduce DC power systems to create and to operate "green facilities" for ICT systems by 2010.

\subsubsection{The 380 VDC Power Supply System}

At the beginning of 2009 , three demonstration sites for 380 Vdc were opened in Tokyo, Japan. Developed 100-kW power systems were installed at each site (see Fig. 26).

The 380 VDC power supply system consists of redundant rectifier modules to convert AC into DC power, storage 


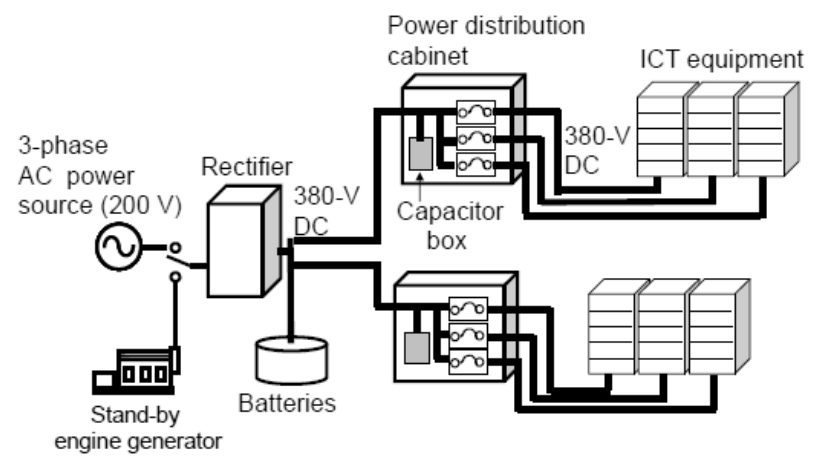

Fig. 27 Configuration of the 380 VDC power supply system.

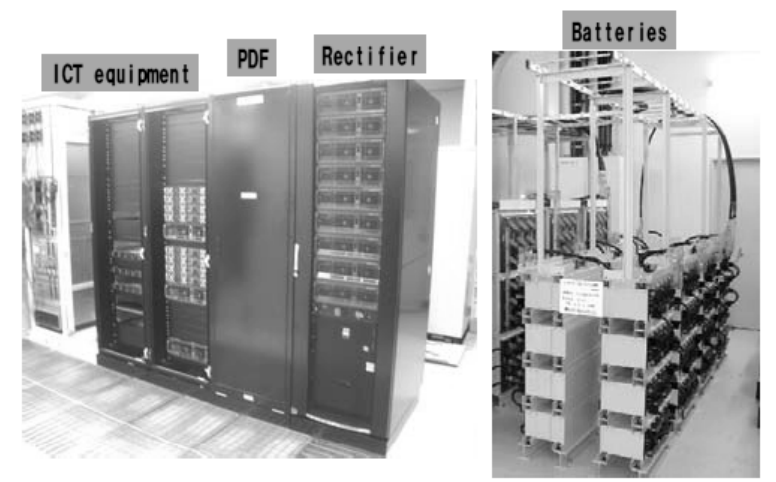

Fig. 28 Overview of the 380 VDC power supply system.

batteries for backup, and a power distribution frame (PDF) to divide primary output into some secondary feeders [114], [115].

The configuration and overview of the $380 \mathrm{VDC}$ power supply system are shown in Fig. 27 and Fig. 28, respectively. The rectifier converts $200 \mathrm{Vac}$ to $400 \mathrm{Vdc}$ and charges the batteries. The PDF distributes the power to ICT equipment.

If the power grid fails, the battery starts to discharge without interruption and disterbane to back-up the load power. In an AC power supply system, the DC power of the battery converts to $\mathrm{AC}$ power and $\mathrm{AC}$ power is supplied to ICT equipment. Dc-ac and ac-dc conversions are necessary to supply sufficient DC power to the components. In a DC power supply system, the battery power directly supplies the ICT equipment. Some conversion is not necessary to supply to ICT equipment. A DC power supply system is very simple. Therefore, it is 10 times more reliable than an AC system. The 380 power supply system is high reliable. Due to rise of the DC voltage from the conventional $-48 \mathrm{~V}$ to aournd $400 \mathrm{~V}$, the supply current can be reduced, as a results, system cost and construction flexibility are improved because smaller diameter power cables can be used.

\subsubsection{Plug \& Socket and Power Strip for 380 Vdc Distri- bution}

NTT Facilities and Fujitsu Component Ltd. developed a power plug \& socket (see Fig. 29) and a power strip for a

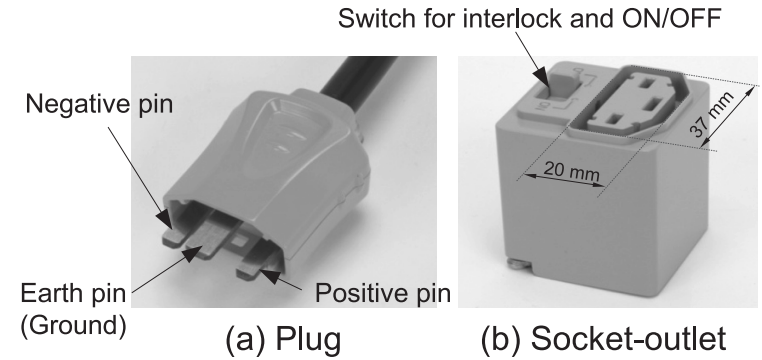

Fig. 29 Plug and socket outlet for 400 VDC power distribution.

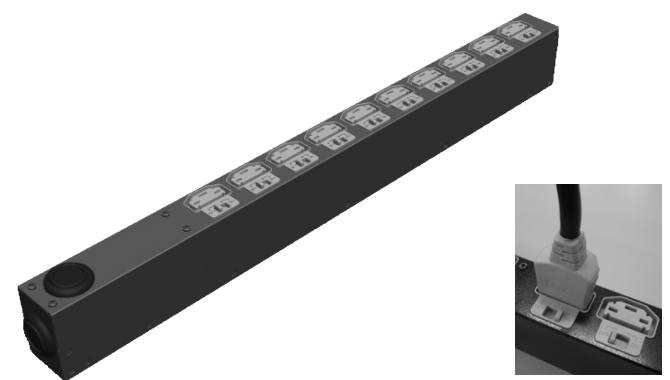

(a) Multiple socket-outlets (b) Inserted plug into a socket-outlet

Fig. 30 Multiple socket-outlets for 400 VDC.

380 Vdc distribution system (see Fig. 30) [116]. The plug $\&$ socket can solve technical problems arising from arc discharge from open/closed-circuits and its influence on the human body and facilities.

For safety reasons, the plug \& socket incorporates a mechanical switch that prevents energization between power plug terminals unless loading apparatuses, such as an ICT device, are being used. When a loading apparatus is used, the power plug is inserted into the socket in the outlet, and then the mechanical switch is switched to "on" so as to close the internal contact. This mechanical switch allows workers and maintenance staff to plug and unplug it without any voltage being applied to it, thus realizing safer operation than current $\mathrm{AC}$ power distribution systems.

The socket is equipped with functions for preventing wrong insertion and unintended unplugging due to tripping. Furthermore, the socket is equipped with an ark blocking module that uses high density magnetic force and forcibly extinguishes the arc when the mechanical switch is switched to "off" before pulling the plug out of the socket.

In addition to these features, the prototype of the power socket consumes almost no power inside the outlet because it is not equipped with semiconductors or complex mechanical components. It is possible to achieve high reliability at a low cost because of the small number of components.

\subsection{Future Works}

An ideal future DC power system is under development. However, some issues will need a lot of effort to be overcome. This section describes two such examples. 


\subsubsection{Prevention of Oscillation}

Today's digital loads, like ICT equipment, have characteristics of negative impedance. Some papers report that voltage oscillation will occur in DC power system with negative impedance [59], [117]. To make sure of stable conditions for DC distribution networks, some tests, simulations, and theorical analysis are required.

\subsubsection{Standardizations of New DC Power System}

For not only safety but also economic reasons, some sets of global standards are essential to introduce new a DC power system [118]. Today, there are no international standards. Some activities to study and issue new standards concerning new DC powering, protections, installations, and works are being considered.

For example, the Swedish national committee briefly introduced a proposal to set up a strategic group on low voltage direct current (LVDC) distribution systems up to $1,500 \mathrm{Vdc}$ in relation to energy efficiency at the International Electrotechnical Committee (IEC) in February 2009. The International Telecommunications Union Standardization Sector (ITU-T) and the European Telecommunications Standards Institute (ETSI) have also started to study the 400 VDC systems.

Some activities for not only ICT system applications, but also commercial and residential buildings have begun. An example in the U.S. is the recently-formed EMerge Alliance [119] to move forward to finalize DC power distribution standards for commercial products before the end of 2009.

\section{Conclusion}

Today, the mission critical facilities such as ICT systems have grown rapidly and the number of digital load devices is increasing, the importance of power supply system is increasing rapidly, too. Therefore, power quality and reliability (PQR) of power supply must be becoming essential in power supply system.

At the same time, distributed energy resources such as solar power, wind energy, and fuel cell are expected to increase for environmental protection and global warming issues. The power distribution system to the mission critical facilities like must solve the instability which is the defect of the renewable energy.

Research and development activities in the field of the $\mathrm{PQR}$ for power supply system are indispensable to cover this technical issues and meet customers requirements.

Microgrids and DC power technologies in new ideas tend to emphasize improving all aspects of both traditional power system and renewable energy resources with improving delivered PQR. On the other hand, improvements could be achieved by controlling PQR more locally, and microgrids and DC power technologies may be suitable for such approach.

\section{References}

[1] T.P. Hughes, translated by N. Ichiba, Networks of Power, Heibonsha, 1996.

[2] Power System Subcommittee of the General Resource and Energy Study Group, Energy Demand in Japan Up to 2030, Ministry of Economy, Trade and Industry, Feb. 2004.

[3] M. Samotyj, D.V. Dollen, and B. Howe, "Powering the digital revolution: Electric power security, quality, reliability, and availability in the digital age," Power Systems and Communications Infrastructures for the Future, Beijing, PRC, Sept. 2002.

[4] M. Amin, "Complex interactive networks/systems initiative: Final summary report," The Electric Power Research Institute (EPRI), March 2003.

[5] Federation of Electric Power Companies of Japan Website, Trends in Number and Duration of Power Outages. http://www.fepc.or.jp/present/supply/antei/sw_index_01/index.html (Accessed 2010-12-08)

[6] Federation of Electric Power Companies of Japan Website, International Comparison of Power Outage Duration. http://www.fepc.or.jp/present/supply/antei/sw_index_02/index.html (Accessed 2010-12-08)

[7] M. Okamura and N. Kobayashi, "Latest trends in power quality technology,” IEEJ Trans. PE, vol.125, no.7, pp.643-646, 2005.

[8] Special Committee for the Study of the EMC Problem for Electrical Power, “The EMC problem for electrical power," IEEJ Technical Reports, no.949, p.46, 2004.

[9] N. Murakami, "Definition of power quality and measurement methods," NTT Facilities Research Institute, 2005 Annual Research Report, 2005.

[10] R.C. Dugan, M.F. McGranaghan, S. Santoso, and H.W. Beauty, Electrical Power Systems Quality, 2nd ed., McGraw-Hill, 2003.

[11] Special Committee on Voltage Dip Countermeasures, "Voltage dip countermeasures," Electric Technology Research Association, vol.46, no.3, 1990.

[12] K. Matsuzaki, "Technical trends in uninterruptable power supplies (Latest trends in UPS 2010)," OHM, vol.97, no.9, pp.64-67, Sept. 2010.

[13] "General survey on new power network technology," NEDO, 2007 Report, New Power Network System Verification Research, March 2008.

[14] Agency for Natural Resources and Energy of the Ministry of Economy, Trade and Industry, Nuclear and Industrial Safety Agency, 2002 Electrical Safety Statistics, Consumer Power Interruption Statistics, July 2004.

[15] H. Hajima, "Power company distribution facilities A la Carte 8 distribution automation system," J. IEIEJ, vol.29, no.7, pp.431435, July 2009.

[16] IEEJ Special Committee on Distribution Grids, "Methods of evaluating distribution grid reliability and technology for decreasing power interruption duration," IEEJ Technical Reports Part 2 , no.298, pp.3-51, May 1989.

[17] T. Maeda, T. Yoshino, and M. Tanaka, Transmission and Distribution, Materials for Power Generation, Tokyo Denki University, 1997.

[18] O. Usuda, "Restoration of the power lifeline after the great Hanshin earthquake,” J. IEEJ, vol.115, no.9, pp.578-581, 1995.

[19] Jukankyou Research Institute, Considering Forum Energy: Report on a Survey of the Effects of Wide-area Power Outages on Consumers, May 2003.

[20] TEPCO press release, "Power outage caused by self-defense force aircraft cutting power lines," Tepco Website (1999-11-22). http://www.tepco.co.jp/cc/press/99112202-j.html (Accessed 201012-08)

[21] "Follow-up news flash! Major Tokyo-area power outage circumstances and countermeasures," OHM, vol.93, no.10, pp.28-31, 
Oct. 2006.

[22] "Data centers not equipped with back-up power supplies are vulnerable to major power outages," NIKKEI COMPUTER, 2006.9.4, p.15, 2006.

[23] Japan Electric Power Information Center, New Zealand Power Outage, "Major power outage in Auckland area (NZ)," International Power Report, vol.40, no.5, pp.43-49, May 1998.

[24] H. Iida, "Power deregulation and successive California power outages," Energy Review, vol.23, no.6, pp.14-17, June 2003.

[25] "What can we learn from major power outages in Europe and North America?: - Speech summary and interview -," J. IEEJ, vol.125, no.1, pp.29-33, 2005.

[26] Center for Financial Industry Information Systems, Auditing and Security, "Effects of the major power outage in the eastern united states on financial institutions," FISC, vol.270, pp.84-95, 2004.

[27] T.R. Karl, J.M. Melillo, and T.C. Peterson, Global Climate Change Impacts in the United States, Cambridge University Press, p.58, 2009.

[28] Amin, Massoud, Financial Impact of World Trade Center Attack, EPRI, DRI-WEFA, Jan. 2002.

[29] M.P. Mills and P. Huber, Critical Power, DIGITAL POWER GROUP, 2003.

[30] Renewable Energy Policy for Building a Low-carbon Society Study Group, Renewable Energy Policy for Building a Low-carbon Society, 2009.

[31] Medium and Long-term Roadmap for Measures against Global Warming Study Group, Energy Supply WG, Current Renewable Energy Policies in Japan and Other Countries, 2010.

[32] M. Usami, M. Matsumoto, T. Ogaki and S. Yokoyama, "Special issue on the latest trends in wind power generation technology," OHM, vol.97, no.5, pp.17-32, May 2010.

[33] S. Watanabe, K. Sugimoto, T. Morita K. Ogimoto, and K. Kushiya, "Special issue on the latest trends in solar power generation technology," OHM, vol.97, no.6, pp.17-42, June 2010.

[34] T. Hirai and N. Fujiwara, "Some problems accompanying expanded introduction of distributed power systems: Focus on the distribution system," J. IEEJ, vol.125, no.3, pp.149-152, 2005.

[35] Y. Fuwa and R. Takinami, "Some problems accompanying the expanded introduction of distributed power systems - Current situation concerning the distribution grid (Special Issue on Power Supply Systems, Including Distributed Power Systems)," Electrical Review, vol.93, no.4, pp.11-15, April 2008.

[36] A. Yokoyama, "Large-capacity wind power generation seen from the grid," J. IEEJ, vol.129, no.5, pp.299-302, 2009.

[37] J.M. Carrasco, L.G. Franquelo, J.T. Bialasiewicz, E. Galvan, R.C.P. Guisado, Ma.A.M. Prats, J.I. Leon, and N. MorenoAlfonso, "Power-electronic systems for the grid integration of renewable energy sources: A survey," IEEE Trans. Ind. Electron., vol.53, no.4, pp.1002-1016, June 2006.

[38] R. Piwko, N. Miller, R. Girad, J. MacDowell,K. Clark, and A. Murdoch, "Generator fault tolerance and grid codes," IEEE Power and Energy Magazine, vol.8, no.2, pp.18-26, March/April 2010.

[39] T. Funabashi, "Technical issues when connecting a distributed power grid and countermeasures," Electrical Review, vol.88, no.3, pp.16-19, 2003.

[40] Ministry of Economy, Trade and Industry, Agency for Natural Resources and Energy, Technical Guidelines for Maintaining Power Quality when Connecting Grids, Oct. 2004.

[41] G. Lawton, "Powering down the computing infrastructure," IEEE Computer Society, Computer, pp.16-19, Feb. 2007.

[42] P. Scheihing, DOE Data Center Energy Efficiency Program, US Department of Energy, April 2009.

[43] W.S. Baer, S. Hassell, and B. Vollaard, Electricity Requirements for a Digital Society, Rand Corp, Nov. 2002.

[44] T. Kudo, "Datacenter, cloud and optical network technology," J. IEICE, vol.93, no.8, pp.669-672, Aug. 2010.

[45] The New York Times Web version, Hiding in Plain Sight, Google
Seeks More Power. http://www.nytimes.com/2006/06/14/technol ogy/ (Accessed 2010-11-09)

[46] Ministry of Economy, Trade and Industry, Green IT Initiative, Dec. 2007.

[47] Ministry of Internal Affairs and Communication, Report of the Study Group on ICT Policy for the Global Warming Problem, April 2008.

[48] US Environmental Protection Agency ENERGY STAR program, Report to Congress on Server and Data Center Energy Efficiency Public Law 109-431, Aug. 2007.

[49] European Telecommunications Network Operators' Association, Energy Task Team First Annual Report; 2005-2007, The Hague, London, April 2008.

[50] Ministry of Economy, Trade and Industry, Law Concerning Rationalization of Energy Use (Japan Law no.49, June 22, 1979) Final Revision: Japan Law no.49, May 2008.

[51] H. Tani and M. Hirada, "NGN era innovation," J. IEEJ, vol.127, no.7, pp.422-425, 2007.

[52] A. Ogasawara, "Energy efficiency of the communication infrastructure required by the information and communication energy problem," Trends in Science and Technology, no.63, pp.10-17, June 2006.

[53] S. Sekiguchi, M. Yuitou, Y. Takeshita, T. Sawada, and S. Nishi, "Methods for evaluating the effects of information and communication services on the environment and an evaluation system," $\mathrm{J}$. IEICE, vol.90, no.3, pp.176-182, March 2007.

[54] Hipp, "Blade computing," Rocky Mountain Institute HighPerformance Data Centers, Sept. 2003.

[55] H. Akagi, S. Kano, and M. Ichimura, "VI \& P and construction technology for communications," NTT Construction, vol.30, no.176, Sept. 1992.

[56] ASHRAE 90427 Document Information, Datacom Equipment Power Trends and Cooling Applications, Jan. 2005.

[57] Telecommunications Power Supply System, Revised ed., Telecommunications Association, Jan. 2002.

[58] H. Ikebe, S. Iwai, T. Tsumura, N. Morii, and K. Hirose, "Efforts to improve the reliability of telecom power," Proc. IEEE 32nd International Telecommunications Energy Conference (INTELEC), Orlando, FL, USA, June 2010.

[59] T. Tanaka, T. Serada, and T. Sakai, "Simulation analysis of dc power-supply system stability," Proc. IEEE Applied Power Electronics Conference, pp.759-764, March 2001.

[60] P.M. Curtis, MAINTAINING MISSION CRITICAL SYSTEMS IN A 24/7 ENVIRONMENT, John Wiley \& Sons, 2007.

[61] "Computers Down: Problems from 2-hour Downtime and Partial Loss of Data Integrity in Google PaaS due to a Power Outage," Nikkei Computer 2010-03-31, vol.753, pp.88-90, March 2010.

[62] Y. Ishigaki, "Results of consumer survey on needs regarding multiple power quality supply system," Institute of Applied Energy, vol.29, no.22, pp.35-40, July 2006

[63] Y. Ishigaki and Oyama, "Results on estimation of the potential market scale from general survey on multiple power quality supply system verification research," IEEJ 2007 Annual Conference, vol.6, 023, 2007.

[64] M. Barnes, J. Kondoh, H. Asano, J. Oyarzabal, G. Ventakaramanan, R. Lasseter, N. Hatziargyriou, and T. Green, "Real-world micro grids-an overview," Proc. Intl Conference on System of Systems Engineering, vol.1, pp.1-8, April 2007.

[65] European Commission, European SmartGrids technology platform, Vision and strategy for Europe's electricity networks of the future, April 2006. http://www.smartgrids.eu/ (Accessed 2010-1208)

[66] H. Kobayashi, "New power network verification research (demand area grid)," J. IEEJ, vol.125, no.3, pp.156-158, 2005.

[67] R. Lasseterm, "Microgrids," IEEE Power Engineering Society Winter Meeting, vol.1, pp.146-149, 2001.

[68] N. Hatziargyriou, H. Asano, R. Iravani, and C. Marnay, "Micro- 
grids," IEEE Power \& Energy Magazine, pp.78-94, July/Aug. 2007.

[69] J. Driesen and F. Katiraei, "Design for distributed energy resources," IEEE Power \& Energy Magazine, vol.6, no.3, pp.30-40, May/June 2008.

[70] T. Goda, Y. Takuma, Y. Izumii, Y. Kojima, E. Takeuchi, and K. Kousaka, Microgrids, Japan Electric Association Press, 2004.

[71] G. Venkataramanan and C. Marnay, "A larger role for microgrids," IEEE Power \& Energy Magazine, vol.6, no.3, pp.78-82, May/June 2008.

[72] E.M. Lightner and S.E. Widergren, "An orderly transition to a transformed electricity system," IEEE Trans. Smart Grid, vol.1, no.1, pp.3-10, June 2010.

[73] A. Yokoyama, "Development of smarter grid (I)," J. IEEJ, vol.130, no.2, pp.94-97, Feb. 2010. (in Japanese).

[74] A. Yokoyama, "Development of smarter grid (II)," J. IEEJ, vol.130, no.3, pp.163-167, March 2010. (in Japanese).

[75] S. Bossart, "Renewable and distributed systems integration demonstration projects," EPRI Smart Grid Demonstration Advisory Meeting, Albuquerque, NM, Oct. 2009.

[76] H. Nara and J. Hasegawa, "New flexible electrical energy delivery system,” IEEJ Trans. PE, vol.117, no.1, pp.47-53, Jan. 1997.

[77] Oyama and R. Hara, "Highly flexible and highly reliable electrical energy delivery system (FRIENDS)," J. IEEJ, vol.125, no.3, pp.159-162, March 2005.

[78] E. Sugihara, Y. Kita, J. Hasegawa, and K. Nishitani, "Evaluation of a multiple-reliability power supply method that takes local characteristics in to account," IEEJ Trans. PE, vol.119, no.3, pp.354-361, March 1999.

[79] Y. Hayashi, K. Tsuji, and T. Ise, "Definition of power quality for a multiple power quality supply system and organization of an AC power improvement center," IEEJ Trans. PE, vol.122, no.12, pp.1384-1394, Dec. 2002.

[80] Y. Mikuri, Y. Kita, R. Hara, E. Tanaka, and J. Hasegawa, "Evaluation of electrical power supply considering the multiple power quality supply system in FRIENDS," IEEJ Trans. PE, vol.124, no.1, pp.43-52, Jan. 2004.

[81] New System Technology Evaluation Subcommittee, Multiple Power Quality Supply System WG, Report on Multiple Power Quality Supply System, IAE-C0241, June 2003.

[82] New Energy and Industrial Technology Development Organization, New Power Network System Verification Research, Report on Multiple Power Quality Supply System, March 2008.

[83] K. Hirose, A. Fukui, A. Matsumoto, et al., "Development of multiple power quality supply system," IEEJ Trans. Electrical and Electronic Engineering, vol.5, no.5, pp.523-530, Sept. 2010.

[84] K. Kuri, Y. Kita, E. Tanaka, and J. Hasegawa, "Effects of introducing FRIENDS taking into account DC distribution on the consumer side," IEEJ Trans. PE, vol.124, no.12, pp.1656-1633, Dec. 2000.

[85] K. Iwadate, W. Goto, et al., "Study for power quality measurement system in the demonstrative project on power suply systems by service level: Power quality measurement and power supply management system," IEEJ Technical Meeting, PE-07-111, vol.104, pp.43-47, July 2007. (in Japanese).

[86] A. Domijan, A. Montenegro, A. Keri, and K. Mattern, "Simulation study of the world's first distributed premium power quality park," IEEE Trans. Power Deliv., vol.20, no.2, pp.1483-1492, April 2005.

[87] K. Hirose, T. Matsumura, and M. Yamasaki, "Cost-benefit analysis of multiple power quality supply systems," IEICE Technical Report, vol.110, no.151, pp.57-62, July 2010. (in Japanese).

[88] The CERTS Microgrid Concept, CONSULTANT REPORT. URL: http://certs.lbl.gov/certs-der-pubs.html (Accessed 2010-12-08)

[89] C. Marnay and O. Bailey, "The CERTS microgrid and the future of the macrogrid," LBNL-55281, Ernest Orlando Lawrence Berkeley National Lab, Aug. 2004.

[90] J. Eto, R. Lasseter, B. Schenkman, J. Stevens, H. Volkommer, and
D. Klapp, Consortium for Electric Reliability Technology Solutions (CERTS), ed. Linton, H. Hurtado, J. Roy, and N.J. Lewis, California Energy Commission, Public Interest Energy Research Program, CEC-500-2009-004, 2008.

[91] New Energy and Industrial Technology Development Organization, 2006 Report: Residential DC power Supply Studies for Fuel Cells, Aug. 2007.

[92] H. Konishi, "DC power supply systems," J. IEEJ, vol.125, no.3, pp.163-164, 2005.

[93] The investigation special committee of the feasibility of direct current distribution network, "The feasibility of direct current distribution network," IEEJ Technical Reports, no.1031, Aug. 2005.

[94] Investigating R\&D Committee on Direct-current distribution and generation of next power system, "Direct-current distribution and generation of next power system," IEEJ Technical Reports, no.1215, March 2011.

[95] My Ton, Brian Fortenbery, W. Tschudi, DC Power for Improved Data Center Efficiency, LBNL Report, Jan. 2007

[96] E.C.W. de Jong, P.T.M. Vaessen, DC power distribution for server farms, KEMA Consulting, Sept. 2007.

[97] N. Tanaka and T. Babasaki, "DC power supply within data centers," J. IEEJ, vol.130, no.5, pp.289-292, May 2010.

[98] S. Muroyama, T. Matsujima, and N. Murakami, "Issues and trends in information and communication power systems," IEICE Trans. Commun. (Japanese Edition), vol.J84-B, no.5, pp.829-839, May 2001.

[99] M. Saisho, T. Ise, and K. Tsuji, "A configuration and control method of DC loop type distribution system including distributed generators," IEEJ Trans. PE, vol.123, no.8, pp.964-973, Aug. 2003.

[100] H. Kakigano, T. Miura, T. Ise, and R. Uchida, "DC micro-grid for super high quality electric power distribution-system configuration and control of distributed generations and energy storage devices," IEEJ Trans. PE, vol.126, no.12, pp.1207-1214, Dec. 2006.

[101] A. Sannino, G. Postiglione, and M. Bollen, "Feasibility of a DC network for commercial facilities," IEEE Trans. Ind. Appl., vol.39, no.5, pp.1499-1507, 2003

[102] “DC Power Production, Delivery and Utilization," EPRI White Paper, May 2006

[103] D. Salomonsson, L. Soder, and A. Sannino, "An adaptive control system for a DC microgrid for data centers," IEEE Trans. Ind. Appl., vol.44, no.6, pp.1910-1917, 2008.

[104] K. Hirose, "Trends of DC power technologies and their applications," IEEJ Trans. PE, vol.131, no.4, pp.358-361, 2011.

[105] J. Jonnes, "Empires of light: Edison, Tesla, Westinghouse, and the race to electrify the world," Random House Trade Paperbacks, 2004.

[106] R. Lobenstein and C. Sulzberger, "Eyewitness to dc history," IEEE Power and Energy Magazine, vol.6, no.3, pp.84-90, 2008.

[107] K. Hirose, "Report on trends in direct current distribution system in Europe," The Journal of Fuel Cell Technology, vol.7, no.1, pp.134140, summer 2007. (in Japanese)

[108] IEEE History Center, "First intelligible voice transmission over electric wire, 1876," online available: http://www.ieee.org/web/ aboutus/history_center/voice.html

[109] U. Carlsson, J. Akerlund, et al., "Powering the InternetBroadband equipment in all facilities - The need for a $300 \mathrm{~V} \mathrm{DC}$ powering and universal current option," IEEE 25th Intelec Proceeding, Yokohama, pp.164-169, 2003.

[110] My ton, B. Fortenbery, and W. Tschudi, "DC power for improved data center efficiency," LBNL Final Report, Jan. 2007.

[111] A. Pratt, P. Kumar, and T.V. Aldridge, "Evaluation of $400 \mathrm{vdc}$ distribution in telco and data centers to improve energy efficiency," Proc. IEEE International Telecommunications Energy Conference, pp.32-39, Sept. 2007.

[112] J. Akerlund, et al., "One year operation of a $9 \mathrm{~kW}$ HVDC UPS 350 $\mathrm{v}$ at Gnesta municipality data center," IEEE 29th Intelec Proceed- 
ing, pp.40-45, Rome, 2007.

[113] Y. Goto, et al., "Integrated management and remote monitoring system for telecommunications power plants with fully DC-powered center equipment," IEEE 29th Intelec Proceeding, pp.775-780, Rome, 2007.

[114] M. Noritake, K. Hirose, M. Yamasaki, T. Oosawa, and H. Mikami, "Evaluation results of power supply to ICT equipment using HVDC distribution system," Proc. IEEE International Telecommunications Energy Conference, PA1-4, June 2010.

[115] T. Babasaki, Toshimitsu Tanaka, Toru Tanaka, Y. Nozaki, T. Aoki, and F. Kurokawa, "Basic characteristics of new developed highervoltage direct-current power-feeding prototype system," IEICE Trans. Commun., vol.E93-B, no.9, pp.2244-2249, Sept. 2010.

[116] S. Baek, T. Yuba, K. Kiryu, A. Nakamura, H. Miyazawa, et al., "Development of plug and socket-outlet for 400 volts direct current distribution system,” Proc. ICPE 2011-ECCE Asia, pp.218-222, Jeju, Korea, May/June 2011

[117] M. Maruyama, K. Hirose, et al., "Stability analysis of high-voltage DC power distribution system including long feeders," EEE 29th Intelec Proceeding, pp.211-215, Rome, 2007.

[118] K. Hirose, M. Yamasaki, and T. Matsumura, "A study on direct current distribution voltage for information and communications systems," IEICE-EE-402, IEICE-CPM-4 03, pp.7-12, Tokyo, Jan. 2009. (in Japanese)

[119] EMerge Alliance, online available: http://www.emergealliance. org/en/index.asp

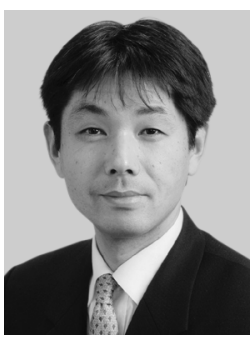

Keiichi Hirose was born in 1967. He received his B.S. in electrical engineering from Yamagata University in 1990 and his M.S. in electrical engineering from Niigata University in 1992. He joined Nippon Telegraph and Telephone corporation in 1992. Since 2004, he has been a senior research engineer at NTT Facilities, Inc. He received his Ph.D. degrees in Electronic Engineering from Nagoya University in 2011. He is actively involved in research of power quality, direct current distribution, and telecommunications power systems. He won the distinguished paper award of the Institute of Electrical Engineers of Japan (IEEJ) in 2010 and the academic paper award of the Institute of Electrical Installation Engineers of Japan (IEIEJ) in 2011. He is a representative member of Japan National Committee of the IEC SMB SG4 (Low voltage DC distribution). He is a member of IEEJ, IEIEJ, and IEEE.

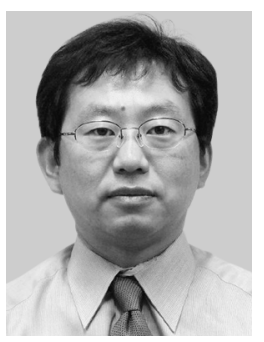

Tatadoshi Babasaki was born in $1965 . \mathrm{He}$ received M.S. and Ph.D. degrees in Electronic Engineering from Nagasaki University in 1990 and 2011, respectively. In 1990, he joined NTT Applied Electronics Research Laboratories. He has been engaged mainly in the DC power feeding system, battery and fuel-cell systems for telecommunication system. He is a member of the IEEJ and IEEE. 